\title{
Fabrication of ILs-Assisted $\mathrm{AgTaO}_{3}$ Nanoparticles for the Water Splitting Reaction: The Effect of ILs on Morphology and Photoactivity
}

\author{
Julia Zwara ${ }^{1}$, Anna Pancielejko ${ }^{2}$, Marta Paszkiewicz-Gawron ${ }^{1}$, Justyna Luczak ${ }^{2}{ }^{\circledR}$, \\ Magdalena Miodyńska ${ }^{1}\left(\mathbb{D}\right.$, Wojciech Lisowski $^{3}$, Adriana Zaleska-Medynska ${ }^{1}(\mathbb{D})$ and \\ Ewelina Grabowska-Musiał ${ }^{1, *}$ \\ 1 Department of Environmental Technology, Faculty of Chemistry, University of Gdansk, \\ 80-308 Gdansk, Poland; julia.zwara@phdstud.ug.edu.pl (J.Z.); m.paszkiewicz-gawron@ug.edu.pl (M.P.-G.); \\ magdalena.miodynska@phdstud.ug.edu.pl (M.M.); adriana.zaleska-medynska@ug.edu.pl (A.Z.-M.) \\ 2 Department of Process Engineering and Chemical Technology, Faculty of Chemistry, Gdansk University of \\ Technology, 80-233 Gdansk, Poland; anna.pancielejko@pg.edu.pl (A.P.); justyna.luczak@pg.edu.pl (J.Ł.) \\ 3 Institute of Physical Chemistry, Polish Academy of Science, 01-244 Warsaw, Poland; wlisowski@ichf.edu.pl \\ * Correspondence: ewelina.grabowska@ug.edu.pl; Tel.: +48-58-523-52-22
}

Received: 3 August 2020; Accepted: 10 September 2020; Published: 12 September 2020

check for updates

\begin{abstract}
The design of an active, stable and efficient photocatalyst that is able to be used for hydrogen production is of great interest nowadays. Therefore, four methods of $\mathrm{AgTaO}_{3}$ perovskite synthesis, such as hydrothermal, solvothermal, sol-gel and solid state reactions, were proposed in this study to identify the one with the highest hydrogen generation efficiency by the water splitting reaction. The comprehensive results clearly show that the solid state reaction (SSR) led to the obtainment of a sample with an almost seven times higher photocatalytic activity than the other methods. Furthermore, four ionic liquids, all possessing nitrogen in the form of organic cations (two imidazoliums with different anions, ammonium and tetrazolium), were used for the first time to prepare composites consisting of $\mathrm{AgTaO}_{3}$ modified with IL and Pt, simultaneously. The effect of the ionic liquids (ILs) and Pt nanoparticles' presence on the structure, morphology, optical properties, elemental composition and the effectiveness of the hydrogen generation was investigated and discussed. The morphology investigation revealed that the $\mathrm{AgTaO}_{3}$ photocatalysts with the application of [OMIM]-cation based ILs created smaller granules $(<500 \mathrm{~nm})$, whereas [TBA] [Cl] and [TPTZ] [Cl] ILs caused the formation of larger particles (up to $2 \mu \mathrm{m}$ ). We found that various ILs used for the synthesis did not improve the photocatalytic activity of the obtained samples in comparison with pristine $\mathrm{AgTaO}_{3}$. It was detected that the compound with the highest ability for hydrogen generation under UV-Vis irradiation was the $\mathrm{AgTaO}_{3} \_.2 \% \mathrm{Pt}\left(248.5 \mu \mathrm{mol} \cdot \mathrm{g}^{-1}\right)$, having an almost 13 times higher efficiency in comparison with the non-modified pristine sample. It is evidenced that the enhanced photocatalytic activity of modified composites originated mainly from the presence of the platinum particles. The mechanism of photocatalytic $\mathrm{H}_{2}$ production under UV-Vis light irradiation in the presence of an $\mathrm{AgTaO}_{3} \_\mathrm{IL} \_\mathrm{Pt}$ composite in the water splitting reaction was also proposed.
\end{abstract}

Keywords: ionic liquids; perovskite; hydrogen production/evolution; photocatalysis; water splitting

\section{Introduction}

All across the world, people are faced everyday with many forms of environmental pollution, such as: water, air and land pollution. These environmental problems affect every human, animal and plant [1-4]. The best solution would be to reduce or even remove the input of pollutants; however, this is impossible. Another very important problem that the world has to face today is the demand 
for energy [5-7]. Therefore, alternative solutions aimed at removing harmful substances from the air, water and soil, as well as ways for the acquisition of clean energy are being searched for [8-11]. One such solution is the application of photoactive material able to remove pollution and/or generate hydrogen in the presence of light with specific radiation. A challenge in the field of heterogeneous photocatalysis is to develop a new type of photoactive materials activated by low-powered and low-cost irradiation sources (also sunlight) [12-14]. Currently, hydrogen is mainly produced from carbon monoxide and natural gas (from fossil fuels) through a steam reforming reaction [15]. However, the risk of fossil fuel depletion, as well as the serious environmental problems associated with $\mathrm{CO}_{2}$ generation, has forced researchers to look for alternative solutions [16]. Recently, great interest has been focused on hydrogen production with a photocatalytic water-splitting reaction in the presence of semiconductor nanoparticles and UV-Vis or solar irradiation [17-22]. The basic requirements for developing photocatalysts for overall water splitting are: (i) sustainable conduction band (CB) and valence band (VB) edge potentials for overall water splitting, (ii) band-gap energy lower than $3 \mathrm{eV}$ for visible-light harvesting, and (iii) photostability in time [23,24].

In this regard, the wide-bandgap semiconductors with $\mathrm{d} 0$ and $\mathrm{d} 10$ configuration such as $\mathrm{Ti}^{4+}$, $\mathrm{Nb}^{5+}$ and $\mathrm{Ta}^{5+}$ are used as photocatalysts for the degradation of pollutants and for hydrogen generation in the reaction of water-splitting $[25,26]$. Until now, the most commonly used materials were titanates (Ti 3d) because of their high ability to reduce water for $\mathrm{H}_{2}$ production. However, it was found that tantalate photocatalysts could be a better candidate since (i) the $\mathrm{Ta}^{5+}$ ion possesses higher reduction potential for hydrogen generation than most of the studied d0 elements [27] and (ii) the bond angle of Ta-O-Ta is close to 180 degrees, providing a high degree of delocalization and excellent mobility [28]. One of the very promising wide-bandgap semiconductors among tantaletes such as $\mathrm{LiTaO}_{3}$ [29], $\mathrm{NaTaO}_{3}[30], \mathrm{KTaO}_{3}[31], \mathrm{CsTaO}_{3}$ [32] is silver tantalate $\left(\mathrm{AgTaO}_{3}\right)$ with a perovskite structure. However, to date, the practical applications of $\mathrm{AgTaO}_{3}$ are limited. It was reported that the $\mathrm{AgTaO}_{3}$ band gap of about $3.4 \mathrm{eV}$ determined the ability to absorb only UV irradiation [33]. An additional problem is the low quantum yield and high recombination rate of the photogenerated charge carriers [34]. The density functional theory (DFT) calculations demonstrated that appropriate N/F co-doping could narrow the band gap of $\mathrm{AgTaO}_{3}$ to $2.9 \mathrm{eV}$ while increasing the charge carrier mobility and the reductive strength towards hydrogen production [34]. Therefore, the following methods for increasing the photocatalytic performance of $\mathrm{AgTaO}_{3}$ were investigated: (i) co-doping [34], (ii) application of semiconductor composites [35] and (iii) modification with noble metals [36]. Among them, enhanced photocatalytic activity for hydrogen generation by the use of a co-catalyst was the most frequently investigated. As a result of the synergy of the interaction between the photocatalyst and the co-catalyst, effective separation of the photogenerated charge carriers occurs, due to changes in the semiconductor electronic structure, such as the band gap width or the position of the valence and the conduction bands. Recently, platinum was found to be the most effective co-catalyst owing to its largest work function and lowest overpotential for $\mathrm{H}_{2}$ evolution [37]. However, up to now, the research has focused mainly on the use of $\mathrm{Ag}$ nanoparticles on the $\mathrm{AgTaO}_{3}$ surface to enhance photocatalytic activity for hydrogen generation. For instance, $\mathrm{Ag}$ nanoparticles deposited on the $\mathrm{AgTaO}_{3}$ surface by means of a simple one-step chemical reduction treatment using ethylene glycol as a reducing agent allowed the preparation of the photocatalyst with a four-time increment for hydrogen production [38]. $\mathrm{Yu}$ et al. described the growth of $\mathrm{Ag}$ nanoparticles onto a $\mathrm{AgTaO}_{3} / \mathrm{SrTiO}_{3}$ solid solution using an in situ exolution procedure with ethylene glycol [39]. The presence of a co-catalyst led to the enhancement of hydrogen generation by nearly $45 \%$ due to the localized surface plasmon effect. Photodeposition of $\mathrm{Ag}$ and $\mathrm{Cu}$ nanoparticles onto $\mathrm{AgTaO}_{3}$ perovskite for improved photocatalytic hydrogen evolution was also reported [36]. According to our knowledge, there are no reports regarding the use of $\mathrm{AgTaO}_{3}$ decoration using Pt nanoparticles for hydrogen evolution.

Another, actually surprising, way to improve the wide-bandgap semiconductor photoactivity under visible light is the use of ionic liquids (ILs) for photocatalyst preparation [40]. Semiconductor modification with ionic liquids is a new, effective approach, but the mechanism of their action is not 
yet fully explained. It is known that ionic liquids form a protective layer on the semiconductor particle surface, thus electrosteric solvation and viscous stabilization of the growing particles occurs [41]. The presence of ionic liquids in the reaction system can also promote the formation of oxygen vacancies, which can be a source of the electronic charge required for $\mathrm{O}_{2}$ adsorption and intermediate energy level [42]. Additionally, ILs as organic compounds possess HOMO-LUMO levels. In this regard, between $\mathrm{TiO}_{2}$, being an n-type semiconductor, and the halogen anion of an IL (where the HOMO orbital is located), new energy levels can be formed [43]. The literature reports that ILs introduced during the preparation of a broadband photocatalyst may increase its activity under visible light due to: (i) doping of non-metal elements (e.g., N, B, F) derived from the IL structure, inducing a narrower band gap and improving the separation efficiency of the photogenerated electron/hole pairs [44]; (ii) it favoring oxygen vacancies [42]; (iii)surface complex charge transfer [45] and (iv) it affecting transport of photogenerated charges [46]. As far as we know, no one has investigated the photocatalytic activity of IL_AgTaO $\mathrm{Ta}_{3}$ loaded with Pt nanoparticles towards hydrogen generation.

Although $\mathrm{AgTaO}_{3}$ has been studied for different applications, no one has reported the comparisons of four different synthesis methods, such as solvothermal (SS), sol-gel (SG), hydrothermal (HS) and solid-state reactions (SSR), to synthesize the photocatalyst with a desirable structure, morphology and enhanced photocatalytic activity using the water splitting reaction. Moreover, for the first time, the effect of ILs differing in structure, namely 2,3,5-triphenyltetrazolium chloride [TPTZ] [Cl], tetrabutylammonium chloride [TBA] [Cl], 1-methyl-3-octylimidazolium tetrafluoroborate [OMIM] $\left[\mathrm{BF}_{4}\right], 1$-methyl-3-octylimidazolium bis (trifluoromethylsulfonyl) imide [OMIM] [Tf $\left.\mathrm{O}_{2} \mathrm{~N}\right]$ (structural formulas shown in Figure 1) and Pt nanoparticles' presence on the morphology and photoactivity of $\mathrm{AgTaO}_{3}$ has been investigated.

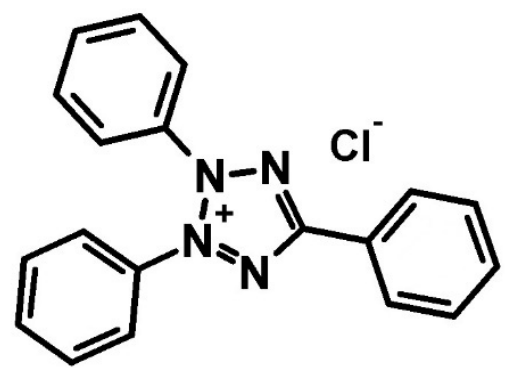

[TPTZ][Cl]

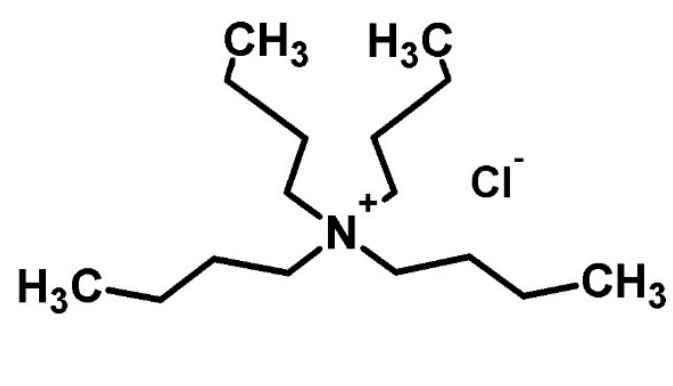

[TBA][Cl]

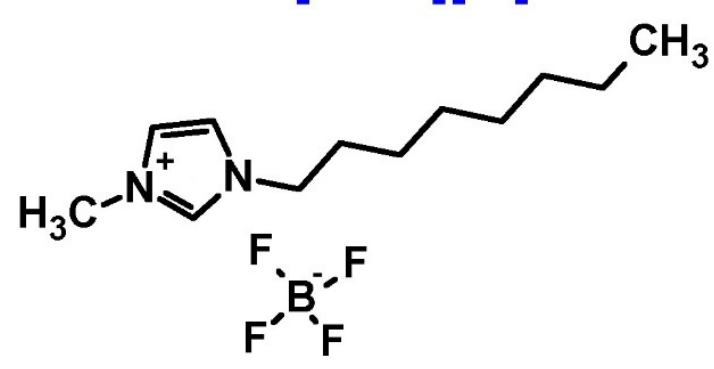

[OMIM] $\left[\mathrm{BF}_{4}\right]$

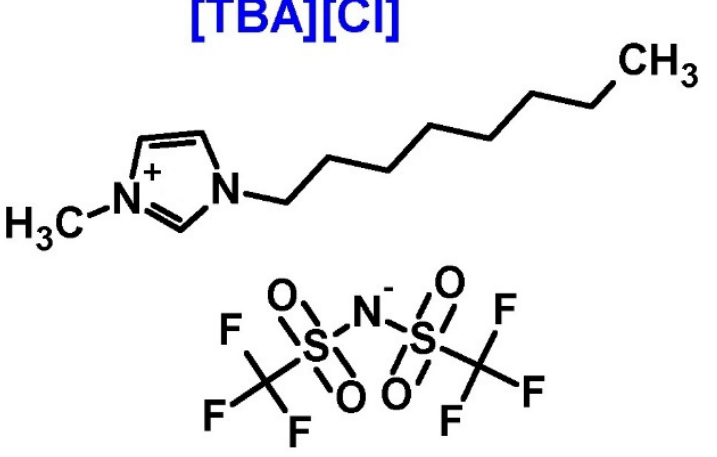

[OMIM] $\left[\mathrm{Tf}_{2} \mathrm{~N}\right]$

Figure 1. Structure of the ionic liquids (ILs) applied during the synthesis of $\mathrm{AgTaO}_{3}$ : 2,3,5-triphenyltetrazolium chloride [TPTZ] [Cl], tetrabutylammonium chloride [TBA] [Cl], 1-methyl-3-octylimidazolium tetrafluoroborate [OMIM] $\left[\mathrm{BF}_{4}\right]$, 1-methyl-3-octylimidazolium bis(trifluoromethylsulfonyl)imide [OMIM] $\left[\mathrm{Tf}_{2} \mathrm{~N}\right]$. 


\section{Materials and Methods}

\subsection{Materials}

Silver nitrate (POCh S.A., Gliwice, Poland), sodium hydroxide (Chempur, Piekary Slaskie, Poland), tantalum oxide (99\%, Sigma Aldrich, Darmstadt, Germany) were used for synthesis of $\mathrm{AgTaO}_{3}$ semiconductors. Ionic liquid, 2,3,5-triphenyltetrazolium chloride [TPTZ] [Cl] $(>98 \%)$ and tetrabutylammonium chloride [TBA] [Cl] $(>97 \%)$ were purchased from Sigma Aldrich (Darmstadt, Germany). 1-methyl-3-octylimidazolium tetrafluoroborate [OMIM] [BF 4 and 1-methyl-3-octylimidazolium bis(trifluoromethylsulfonyl)imide [OMIM] $\left[\mathrm{Tf}_{2} \mathrm{~N}\right]$ with a purity of $>99 \%$ from Iolitec (Heilbronn, Germany).

\subsection{Preparation of $\mathrm{AgTaO}_{3}$}

At first, we decided to use four different methods, namely solvothermal, sol-gel, hydrothermal and solid state reactions to prepare the perovskite. The applied synthesis procedures were as follows:

- Preparation of $\mathrm{AgTaO}_{3}$ by the solvothermal method. The $\mathrm{AgTaO}_{3}$ powder was obtained as follows: $0.95 \mathrm{~g} \mathrm{AgNO}_{3}$ was dissolved in $120 \mathrm{~mL}$ of ethylene glycol and then $2.02 \mathrm{~g} \mathrm{TaCl}_{5}$ was added. The solution was stirred for $15 \mathrm{~min}$. The resulting mixture was transferred into a Teflon-lined stainless steel autoclave (LabPartner, Warsaw, Poland) and treated at $180^{\circ} \mathrm{C}$ for $24 \mathrm{~h}$. After cooling to room temperature, the obtained precipitate was separated by centrifugation, washed several times with deionized water, dried overnight at $60^{\circ} \mathrm{C}$ and finally calcined at $800{ }^{\circ} \mathrm{C}$ for $4 \mathrm{~h}$.

- Preparation of $\mathrm{AgTaO}_{3}$ by the sol-gel method. In the first step $2 \mathrm{~g}$ of $\mathrm{AgNO}_{3}$ was dissolved in $50 \mathrm{~mL}$ of deionized water and $4.19 \mathrm{~g}$ of $\mathrm{TaCl}_{5}$ was added. The mixture was kept under constant stirring conditions and $20 \mathrm{~mL} \mathrm{NH}_{4} \mathrm{OH}$ was added dropwise to the above mixture. After stirring for $1 \mathrm{~h}$, the resulting dark precipitate was separated by centrifugation, washed several times with deionized water and then dried at $60^{\circ} \mathrm{C}$ until the liquid had completely evaporated. The obtained powder was further annealed at $800^{\circ} \mathrm{C}$ for $2 \mathrm{~h}$.

- Preparation of $\mathrm{AgTaO}_{3}$ by the hydrothermal method. In the hydrothermal route, $\mathrm{Ag}_{2} \mathrm{O}$ was first obtained. As in typical synthesis, $\mathrm{NaOH}(0.1 \mathrm{M})$ was slowly added under stirring conditions to $\mathrm{AgNO}_{3}(0.1 \mathrm{M})$. Then, the brown precipitation was collected and washed with deionized water several times, and dried overnight at $60^{\circ} \mathrm{C}$. The as-prepared $\mathrm{Ag}_{2} \mathrm{O}$ powder was mixed with $\mathrm{Ta}_{2} \mathrm{O}_{5}$, $\mathrm{NH}_{4} \mathrm{HF}_{2}, \mathrm{H}_{2} \mathrm{O}$ and $\mathrm{H}_{2} \mathrm{O}_{2}$. The solution was mixed for $10 \mathrm{~min}$, transferred into a Teflon-lined stainless steel autoclave and treated at $180{ }^{\circ} \mathrm{C}$ for $24 \mathrm{~h}$. After cooling to room temperature, the obtained precipitate was separated by centrifugation, washed several times with deionized water and dried overnight at $60^{\circ} \mathrm{C}$.

- Preparation of $\mathrm{AgTaO}_{3}$ by the solid state reaction. The precursor, $\mathrm{Ag}_{2} \mathrm{O}$, was first obtained as described above. The as-prepared $\mathrm{Ag}_{2} \mathrm{O}$ was mixed with $\mathrm{Ta}_{2} \mathrm{O}_{5}$ in a stoichiometric ratio in the presence of $\mathrm{Ag}_{2} \mathrm{O}$ and ground by hand in an agate mortar. It is known that silver-based materials suffer a loss of silver at high calcination temperature. Therefore, to overcome this drawback, $3.0 \mathrm{wt} \%$ of $\mathrm{Ag}_{2} \mathrm{O}$ was added in excess to maintain the required stoichiometry [33,47]. The mixture was calcinated in air at $900{ }^{\circ} \mathrm{C}$ for $24 \mathrm{~h}$, with a heating rate of $1{ }^{\circ} \mathrm{C} \cdot \mathrm{min}^{-1}$. After this process, the sample was naturally cooled down in a furnace to the ambient temperature.

\subsection{Modification of $\mathrm{AgTaO}_{3}$ with IL and Co-Catalyst Pt by Using the Photodeposition Method}

The IL-modified $\mathrm{AgTaO}_{3}$ powders were successfully prepared via a solid state reaction by homogenization $\mathrm{Ag}_{2} \mathrm{O}, \mathrm{Ta}_{2} \mathrm{O}_{5}$ and IL in mortar (molar ratio of $\mathrm{Ag}_{2} \mathrm{O}$ to IL was constant and equaled 1:2) and calcinated at $900{ }^{\circ} \mathrm{C}$ for $24 \mathrm{~h}$ with a heating rate of $1^{\circ} \mathrm{C} \cdot \mathrm{min}^{-1}$ (see Preparation of $\mathrm{AgTaO}_{3}$ by Solid State Reaction).

A suspension containing $\mathrm{AgTaO}_{3}$ or $\mathrm{AgTaO}_{3} \mathrm{IL}(2 \mathrm{~g}), 70 \mathrm{~mL}$ of ethanol solution and the platinum precursor $\mathrm{K}_{2} \mathrm{PtCl}_{4}(0.2 \mathrm{wt} \%$ of $\mathrm{Pt})$ was placed in a quartz reactor and sonicated for $10 \mathrm{~min}$. Then, 
the solution was degassed with nitrogen $\left(8 \mathrm{dm}^{3} \cdot \mathrm{h}^{-1}\right)$ and stirred in the dark for $30 \mathrm{~min}$. The as-prepared suspension was irradiated with an Xe lamp ( $250 \mathrm{~W}$, Heraeus Noblelight GmbH, Cambridge, UK) used as an irradiation source of UV for $1 \mathrm{~h}$. The obtained samples were separated by centrifugation, sequentially rinsed with deionized water, and dried at $60^{\circ} \mathrm{C}$ for $12 \mathrm{~h}$. The specific concentration of platinum in the suspension was selected based on our previous research [48].

\subsection{Characterization of Materials}

The crystal structure of the samples obtained was characterized by the X-ray powder diffraction method (XRD, Rigaku MiniFlex 600, Rigaku, The Woodlands, TX, USA) measured in the $2 \theta$ range of $20-80^{\circ}$ with the target $\mathrm{Cu} \mathrm{K} \alpha$ irradiation. The mean crystallite size from the Scherrer equation was also estimated. The shape and size of the particles were observed by scanning electron microscopy (SEM, JEOL JSM-7610F, Jeol Ltd., Tokyo, Japan). The surface content of the samples was determined by X-ray photoelectron spectroscopy (XPS, PHI 5000 VersaProbe $^{\mathrm{TM}}$, ULVAC-PHI, Chigasaki, Japan) with a source of monochromatic $\mathrm{Al} \mathrm{K} \alpha$ irradiation $(\mathrm{h} v=1486.6 \mathrm{eV})$. High-resolution spectra (HR-XPS) were measured using a hemispherical analyzer (transition energy $23.5 \mathrm{eV}$, energy step size $0.1 \mathrm{eV}$ ). The recorded $\mathrm{C} 1 \mathrm{~s}$ spectrum of carbon was used as reference for binding energy $(284.8 \mathrm{eV})$. The BET (Gemini V (model 2365)) surface area was determined by a multipoint method with the use of adsorption data in the relative pressure $(\mathrm{P} / \mathrm{P0})$ range of $0.05-0.3$ after degassing the samples at $200{ }^{\circ} \mathrm{C}$. The diffuse reflectance spectra (UV-Vis) were recorded with a spectrophotometer (Evolution 220, Thermo Fisher Scientific, Waltham, MA, USA) in the scanning range of $200-900 \mathrm{~nm}$. The spectrophotometer was equipped with an integrating sphere accessory for diffuse reflection with the baseline performed using barium sulphate. Fourier transformed infrared spectra (FTIR) were obtained with a Nicolet iS10 FTIR spectrometer in a scanning range of $500-4000 \mathrm{~cm}^{-1}$ with a resolution of $4 \mathrm{~cm}^{-1}$. Before analysis, the samples were prepared by diluting in $\mathrm{KBr} 5 \%$ of the photocatalysts. Raman spectra were recorded a DXR Smart Raman on spectrometer. A laser emitting irradiation with a wavelength of $532 \mathrm{~nm}$ was used as the excitation source.

\subsection{Measurements of Photocatalytic Activity in Water-Splitting Reaction}

The photocatalytic hydrogen evolution experiments were carried out in a tightly closed cylindrical quartz reactor. In a typical experiment, the photocatalyst $(0.1 \mathrm{~g})$ was dispersed with continuous stirring (700 rpm) in an aqueous methanol solution $(80 \mathrm{~mL}, \mathrm{C}=10 \%)$, which was used as a sacrificial reagent for holes $\left(\mathrm{h}^{+}\right)$. The process was carried out at a constant temperature of $10^{\circ} \mathrm{C}$ set by a thermostatically controlled water bath. The space above the suspension was purged with nitrogen for $30 \mathrm{~min}$ to remove residual oxygen, and then the system was irradiated with a $1000 \mathrm{~W}$ Xe lamp (Oriel Instruments, Stratford, CT, USA) which emitted UV-Vis irradiation. The evolved gas $(200 \mu \mathrm{L})$ was collected through the septum at regular time intervals every $60 \mathrm{~min}$ using a gas-tight syringe. The total exposure time of the sample was $240 \mathrm{~min}$ (in the case of testing, the exposure time of the most photoactive composite was $20 \mathrm{~h}$ ). The amount of hydrogen generated in the tested samples was analyzed using a gas chromatograph (Trace 1300, Thermo Fisher Scientific, Waltham, MA, USA) equipped with a thermal conductivity detector (TCD) with $\mathrm{N}_{2}$ as the carrier gas and with a column (HayeSep Q (80/100)). Hydrogen generation was determined by a blank test in the absence of a photocatalyst, where evolution of $\mathrm{H}_{2}$ was not observed. The specific conditions for conducting the hydrogen generation process (type and concentration of sacrificial agent ( $10 \%$ methanol) as well as the amount of the photocatalyst $(0.1 \mathrm{~g}))$ were established based on our previous research [48]. Additionally, the measurement with a glass filter (GG420, Optel, Opole, Poland) cutting off wavelengths shorter than $420 \mathrm{~nm}$ revealed no hydrogen generation.

\section{Results and Discussion}

Firstly, the preparation routes of the $\mathrm{AgTaO}_{3}$ synthesis was taken into consideration. Four different methods were applied, and based on the obtained results, including crystallite size (Table S1) and 
hydrogen evolution in the water splitting reaction (see Table S1, Figure 2), it was concluded that the technique which led to the obtainment of $\mathrm{AgTaO}_{3}$ with the smallest crystallite size, and thus with the highest ability to generate hydrogen, was SSR in comparison with the other methods-SS, HS, SSR and SG. Therefore, we decided to select SSR for the preparation of the IL-modified samples followed by surface decoration with Pt particles using the photodeposition method.

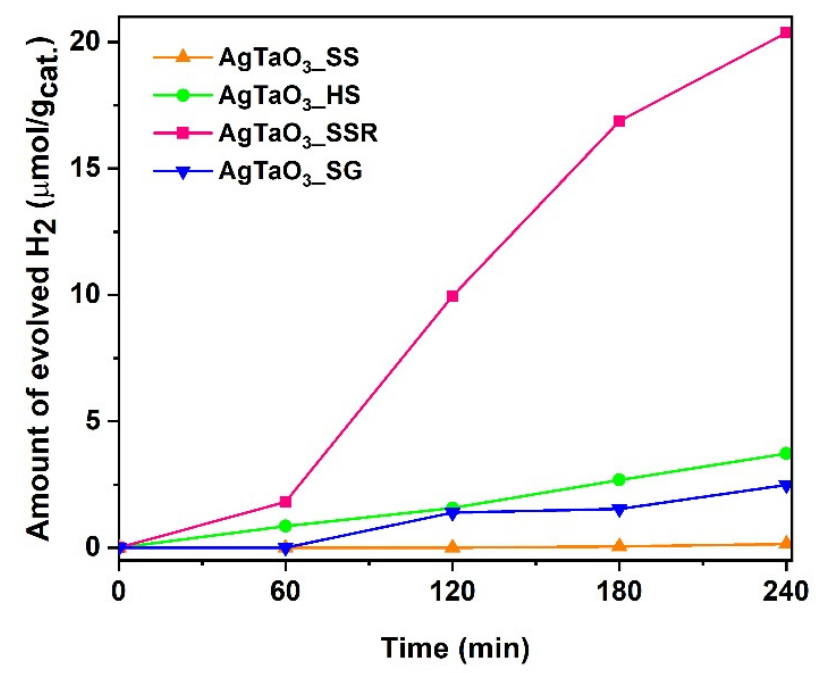

Figure 2. Efficiency of $\mathrm{H}_{2}$ generation determined for $\mathrm{AgTaO}_{3}$ prepared via different methods, namely solvothermal synthesis $\left(\mathrm{AgTaO}_{3} \_\mathrm{SS}\right)$, hydrothermal synthesis $\left(\mathrm{AgTaO}_{3} \_\mathrm{HS}\right)$, solid state reaction $\left(\mathrm{AgTaO}_{3} \_\mathrm{SSR}\right)$ and sol-gel $\left(\mathrm{AgTaO}_{3} \_\mathrm{SG}\right)$.

At the next step, the effect of the ILs' structure on the crystalline structure, morphology and photoactivity of $\mathrm{AgTaO}_{3}$ was considered, and four different ILs were chosen, namely [TPTZ][Cl], [TBA] $[\mathrm{Cl}]$ and $[\mathrm{OMIM}]\left[\mathrm{BF}_{4}\right],[\mathrm{OMIM}]\left[\mathrm{Tf}_{2} \mathrm{~N}\right]$. The molar ratio of ILs to $\mathrm{Ag}_{2} \mathrm{O}$ was constant and equaled 1:2. Based on our previous research on the perovskite materials, we selected the amount of platinum precursor at the level of $0.2 \mathrm{wt} \%$ [48].

\subsection{Morphology}

The microstructures of as-prepared powders were inspected under electron microscopy conditions. Typical SEM images of the following samples (a) pristine $\mathrm{AgTaO}_{3}$, (b) $\mathrm{AgTaO}_{3}[\mathrm{OMIM}][\mathrm{BF} 4]$ (c) $\mathrm{AgTaO}_{3}[\mathrm{OMIM}]\left[\mathrm{Tf}_{2} \mathrm{~N}\right] \_0.2 \% \mathrm{Pt}$, (d) $\mathrm{AgTaO}_{3}[\mathrm{TBA}][\mathrm{Cl}] \_0.2 \% \mathrm{Pt}$, (e) $\mathrm{AgTaO}_{3}[\mathrm{TPTZ}][\mathrm{Cl}] \_.2 \% \mathrm{Pt}$ are shown in Figure 3. The obtained powder samples consisted of irregular particles with a smooth surface where the size and shape depended on the ionic liquids. It was found that pristine $\mathrm{AgTaO}_{3}$ and that modified with both $[\mathrm{OMIM}]\left[\mathrm{BF}_{4}\right]$ and $[\mathrm{OMIN}]\left[\left[\mathrm{Tf}_{2} \mathrm{~N}\right]\right.$ ionic liquids and Pt nanoparticles were composed of granules smaller than $500 \mathrm{~nm}$ (Figure 3a-c). The particles size increased up to $2 \mu \mathrm{m}$ when $\mathrm{AgTaO}_{3}$ was modified by [TBA][Cl] and [TPTZ][Cl] (Figure 3d,e). What is more, the formation of asymmetrical cubes for those samples was observed. 


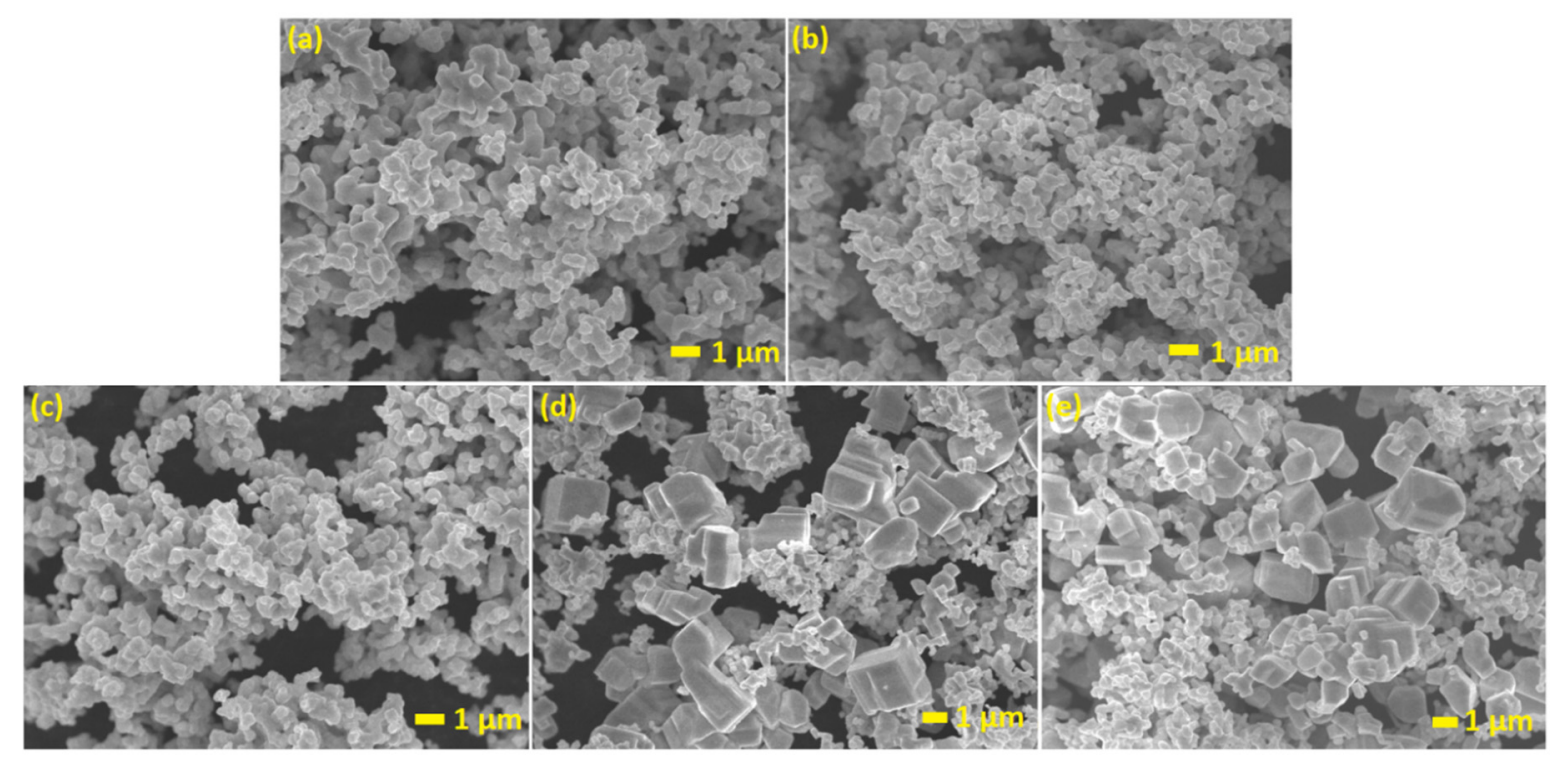

Figure 3. SEM images of: (a) pristine $\mathrm{AgTaO}_{3}$, (b) $\mathrm{AgTaO}_{3}[\mathrm{OMIM}]\left[\mathrm{BF}_{4}\right] \_0.2 \% \mathrm{Pt}$, (c) $\mathrm{AgTaO}_{3}$ _[OMIM] $\left[\mathrm{Tf}_{2} \mathrm{~N}\right] \_0.2 \% \mathrm{Pt}$, (d) $\mathrm{AgTaO}_{3}[\mathrm{TBA}][\mathrm{Cl}] \_0.2 \% \mathrm{Pt}$, (e) $\mathrm{AgTaO}_{3}[\mathrm{TPTZ}][\mathrm{Cl}] 0.2 \% \mathrm{Pt}$.

\subsection{The XRD and BET Analyses}

The XRD patterns of the as-prepared samples are shown in Figure 4. The peaks near $22.8^{\circ}$, $32.6^{\circ}, 46.3^{\circ}, 52.2^{\circ}, 57.7^{\circ}, 72.4^{\circ}$ and $76.9^{\circ}$ corresponded to a pure phase of $\mathrm{AgTaO}_{3}$. Calcination of these samples at $900{ }^{\circ} \mathrm{C}$ for $24 \mathrm{~h}$ led to the formation of $\mathrm{AgTaO}_{3}$ nanoparticles with a rhombohedral perovskite type structure with R3c space group. The refined lattice parameters $a, b$ and c, unit cell volume, and average crystallite size are gathered in Table 1 . The addition of an IL to the reaction environment caused changes in the intensity of the (104) peak in comparison with the pristine sample. The samples prepared in the presence of [TPTZ] [Cl] and [TBA] [Cl] possessed additional peaks which could originate from the ILs residual impurities. Decoration with Pt nanoparticles did not have any influence on the peak position, which indicated that $\mathrm{Pt}$ was deposited on the surface instead of being inserted in the crystal lattice of $\mathrm{AgTaO}_{3}$. Furthermore, no peaks derived from Pt were observed. This is probably due to their high dispersion and low content on the $\mathrm{AgTaO}_{3}$ photocatalyst. The average crystallite size was estimated based on the Scherer equation. The discrepancies in the crystallite sizes of the modified samples in comparison with the reference $\mathrm{AgTaO}_{3}$ are thought to originate from the presence of different ILs structures and the results were collected in Table 1. As can be observed, especially in the case of [TPTZ] [Cl], the increase in crystallite size was the largest, and changed from 215.4 to $294.5 \AA$, for $\mathrm{AgTaO}_{3}$ and $\mathrm{AgTaO}_{3}[\mathrm{TPTZ}]$ [Cl], respectively. Moreover, it was observed that for $\mathrm{AgTaO}_{3}{ }_{0} 0.2 \% \mathrm{Pt}$, and $\mathrm{AgTaO}_{3}[\mathrm{OMIM}]\left[\mathrm{Tf}_{2} \mathrm{~N}\right]_{-} 0.2 \% \mathrm{Pt}$, the average crystallize size increased, from 215.4 to $259.4 \AA$ and from 218.2 to $262.8 \AA$, respectively. However, for the rest of the samples modified by ILs and $\mathrm{Pt}$, a decrease in average crystallite size was observed. Regarding the specific surface area, the results determined for $\mathrm{AgTaO}_{3}[\mathrm{OMIM}]\left[\mathrm{BF}_{4}\right]$ and $\mathrm{AgTaO}_{3}[\mathrm{OMIM}]\left[\mathrm{Tf}_{2} \mathrm{~N}\right]$ were around 0.87 and $1.12 \mathrm{~m}^{2} \cdot \mathrm{g}^{-1}$, respectively, whereas the area of the pristine $\mathrm{AgTaO}_{3}$ sample equaled $0.92 \mathrm{~m}^{2} \cdot \mathrm{g}^{-1}$ (as presented in Table 1). When the [TBA] [Cl] and [TPTZ] [Cl] were added into the reaction environment, the specific surface area of the modified perovskites equaled $0.56 \mathrm{~m}^{2} \cdot \mathrm{g}^{-1}$ for $\mathrm{AgTaO}_{3}[\mathrm{TBA}][\mathrm{Cl}]$ and $0.7256 \mathrm{~m}^{2} \cdot \mathrm{g}^{-1}$ for $\mathrm{AgTaO}_{3}[\mathrm{TPTZ}]$ [Cl]. Moreover, Pt surface deposition resulted in an increase in the specific surface area for $\mathrm{AgTaO}_{3} 0.2 \% \mathrm{Pt}\left(1.1408 \mathrm{~m}^{2} \cdot \mathrm{g}^{-1}\right), \mathrm{AgTaO}_{3}[\mathrm{OMIM}]$ [BF4]_0.2\% Pt $\left(1.0362 \mathrm{~m}^{2} \cdot \mathrm{g}^{-1}\right)$ and $\mathrm{AgTaO}_{3}[\mathrm{TBA}][\mathrm{Cl}] \_0.2 \% \mathrm{Pt}\left(0.7214 \mathrm{~m}^{2} \cdot \mathrm{g}^{-1}\right)$, whereas for the rest, BET surface area decreased (see Table 1 ). 


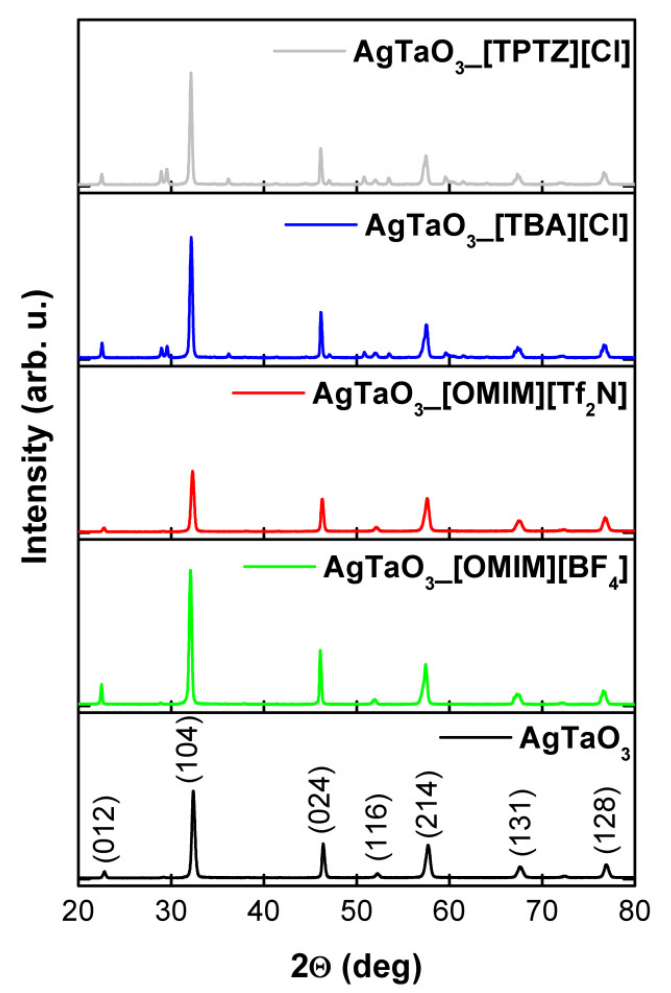

Figure 4. XRD patterns of pristine and IL-modified $\mathrm{AgTaO}_{3}$ samples.

Table 1. Parameters, average crystallite size and specific surface area.

\begin{tabular}{|c|c|c|c|c|c|c|}
\hline Sample Label & $a=b(A)$ & c (A) & $V\left(A^{3}\right)$ & $\begin{array}{l}\text { Crystallite } \\
\text { Size (A) }\end{array}$ & $\begin{array}{l}\text { Specific Surface Area } \\
\qquad\left(\mathrm{m}^{2} \cdot \mathrm{g}^{-1}\right)\end{array}$ & $\begin{array}{l}\text { Amount of } \mathrm{H}_{2} \text { Evolved after } \\
240 \mathrm{~min}\left(\mu \mathrm{mol} \mathrm{g}^{-1}\right) \text { under } \\
\text { UV-Vis Irradiation }\end{array}$ \\
\hline $\mathrm{AgTaO}_{3}$ & 5.4923 & 13.7718 & 359.78 & 215.4 & 0.9226 & 20.4 \\
\hline $\mathrm{AgTaO}_{3}[\mathrm{OMIM}]\left[\mathrm{Tf}_{2} \mathrm{~N}\right]$ & 5.5300 & 13.6315 & 361.01 & 218.2 & 1.1184 & 21.3 \\
\hline $\mathrm{AgTaO}_{3-}[\mathrm{TBA}][\mathrm{Cl}]$ & 5.5415 & 13.7251 & 364.54 & 267.6 & 0.5617 & 11.3 \\
\hline $\mathrm{AgTaO}_{3}[\mathrm{TPTZ}][\mathrm{Cl}]$ & 5.5482 & 13.6898 & 359.78 & 294.5 & 0.7193 & 3.7 \\
\hline $\mathrm{AgTaO}_{3} \_[\mathrm{OMIM}]\left[\mathrm{Tf}_{2} \mathrm{~N}\right] \_0.2 \% \mathrm{Pt}$ & 5.5673 & 13.7832 & 369.97 & 262.2 & 1.0342 & 221.2 \\
\hline $\mathrm{AgTaO}_{3-}[\mathrm{TBA}][\mathrm{Cl}] \_.2 \% \mathrm{Pt}$ & 5.5250 & 13.6974 & 362.11 & 243.8 & 0.7124 & 25.1 \\
\hline $\mathrm{AgTaO}_{3}[\mathrm{TPTZ}][\mathrm{Cl}] \_0.2 \% \mathrm{Pt}$ & 5.5345 & 13.7027 & 364.84 & 284.1 & 0.6986 & 55.4 \\
\hline
\end{tabular}

\subsection{The XPS Analyses}

The elemental composition in the surface region of pristine $\mathrm{AgTaO}_{3}$ and the IL-modified $\mathrm{AgTaO}_{3} \_.2 \%$ Pt composites was determined by XPS and collected in Table 2. The HR spectra of Ag 3d, $\mathrm{Ta} 4 \mathrm{f}$ and $\mathrm{Pt} 4 \mathrm{f}$, presented in Figure 5, identify well $\mathrm{Ag}$, Ta and $\mathrm{Pt}$ as main elements of these samples [49]. Detection of fluorine (F1s spectrum) and boron (B1s spectrum) in $\mathrm{AgTaO}_{3}[\mathrm{OMIM}]\left[\mathrm{BF}_{4}\right]$ and fluorine and sulphur (S2p spectrum) in $\mathrm{AgTaO}_{3-}[\mathrm{OMIM}]\left[\mathrm{Tf}_{2} \mathrm{~N}\right]$ evidences the successful modification of $\mathrm{AgTaO}_{3}$ Pt samples by [OMIM] [ $\left.\mathrm{BF}_{4}\right]$ and [OMIM] [ $\left.\mathrm{Tf}_{2} \mathrm{~N}\right]$ ionic liquids, respectively. The $\mathrm{Cl} 2 \mathrm{p}$ spectra recorded on $\mathrm{AgTaO}_{3}[\mathrm{TPTZ}][\mathrm{Cl}]$ and $\mathrm{AgTaO}_{3}[\mathrm{TBA}][\mathrm{Cl}]$ samples confirm the successful modification of $\mathrm{AgTaO}_{3}$ with [TPTZ] [Cl] and [TBA] [Cl] IL, respectively. However, nitrogen, originated from all IL dopants, was detected in the BE region of $\mathrm{N} 1$ s overlapped by intensive Ta $4 \mathrm{p}_{3 / 2}$ signals. Thus, the deconvolution of these complex spectra was necessary to evaluate the nitrogen content in all samples (Table 2). Similarly, the Pt $4 \mathrm{f}$ spectra were partially overlapped by the Ta 5 s signals. However, after deconvolution, three $\mathrm{Pt}$ states were identified, represented by $\mathrm{Pt} 4 \mathrm{f}_{7 / 2}$ signals, located at $\mathrm{BE}$ of 69.9-70.2, 70.8-71.4 and 71.8-72.7 eV (see Pt 4f $\mathrm{f}_{7 / 2}$ fractions named as Pt1, Pt2 and Pt3, respectively in Table 2). The first Pt state (Pt1) is addressed to Pt-Ag bonds formed as a result of the Pt interaction with $\mathrm{AgTaO}_{3}[49]$, the second (Pt2) can be attributed to $\mathrm{Pt}(0)$ and $\mathrm{Pt}-\mathrm{CO}$ adsorbate and the last one (Pt3) we 
assign to Pt bound formed by $\mathrm{CxHy}$ and IL surface species interacting with $\mathrm{AgTaO}_{3}$ [49]. The Pt1 state is a dominant fraction of $\mathrm{Pt}$ compounds in the surface region of all samples. It is interesting to note that both chloride composites, namely $\mathrm{AgTaO}_{3}[\mathrm{TBA}][\mathrm{Cl}]$ and $\mathrm{AgTaO}_{3}[\mathrm{TPTZ}]$ [Cl], exhibit a larger platinum content than the other samples (Table 2), which suggests the segregation of $\mathrm{Pt}$ to the surface region of these samples. This supposition is supported by the $\mathrm{Pt} / \mathrm{Ag}$ ratios of both samples, being about two times higher than the other ones (Table 2). The larger surface amount of $\mathrm{Pt}$ in these samples is accompanied by a larger amount of carbon species (see C/Ag ratios of both samples in Table 2), which indicates a larger concentration of IL at the surface. The increased amount of IL adsorbate is also detectable in the $\mathrm{Pt} 4 \mathrm{f}$ spectra of both samples. We observed a relative decrease in Pt1 and an increase in Pt3 fractions contributing to the Pt $4 \mathrm{f}$ spectra (Table 2).

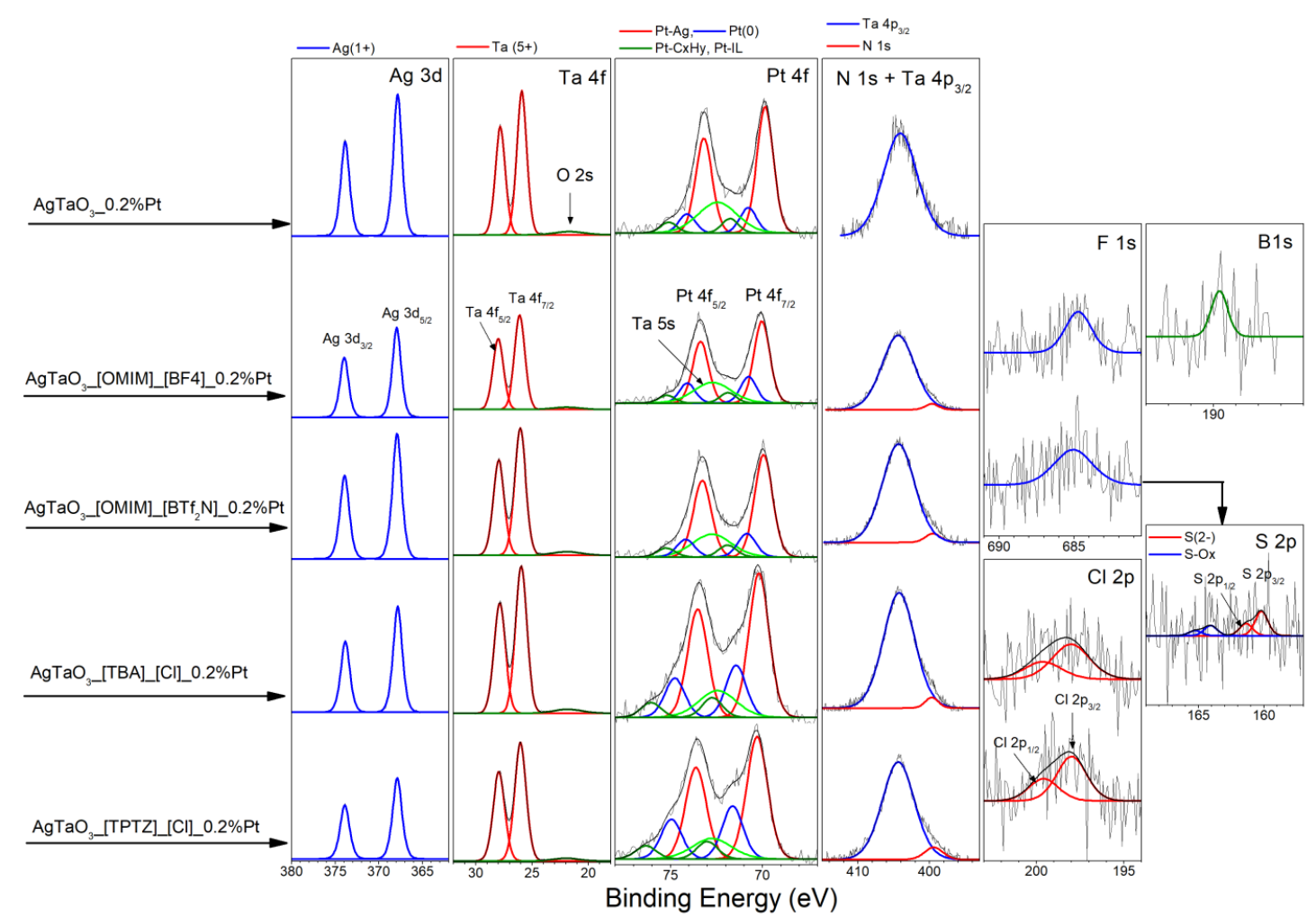

Figure 5. The high resolution XPS spectra of elements detected in $\mathrm{AgTaO}_{3}$ - $0.2 \% \mathrm{Pt}$ and IL-modified $\mathrm{AgTaO}_{3} 0.2 \%$ Pt composites. 
Table 2. Elemental contents in the surface layer of $\mathrm{AgTaO}_{3}$ and $\mathrm{AgTaO}_{3} \mathrm{IL}_{-}$composites doped by Pt. The Pt1, Pt2 and Pt3 fractions of the Pt $4 \mathrm{f}_{7 / 2} \mathrm{XPS}$ spectra indicate the relative contribution of platinum species.

\begin{tabular}{|c|c|c|c|c|c|c|c|c|c|c|c|c|c|c|c|}
\hline \multicolumn{13}{|c|}{-} & \multicolumn{3}{|c|}{$\operatorname{Pt} 4 \mathrm{f}_{7 / 2}$ Fraction $(\%)$} \\
\hline- & & & & Elen & ents $C_{C}$ & ntent & at.\%) & & & & & & Pt1 & Pt2 & Pt3 \\
\hline Sample Label & Ag & Ta & $\mathbf{O}$ & $\mathbf{P t}$ & $\mathrm{C}$ & $\mathbf{F}$ & B & $\mathrm{S}$ & $\mathrm{Cl}$ & $\mathbf{N}$ & $\mathrm{Pt} / \mathrm{Ag}$ & C/Ag & $\begin{array}{c}\text { Pt-Ag } \\
69.9-70.2 \mathrm{eV}\end{array}$ & $\begin{array}{l}\mathrm{Pt}(0), \mathrm{Pt}-\mathrm{CO} \\
70.8-71.4 \mathrm{eV}\end{array}$ & $\begin{array}{c}\text { Pt-CxHy, Pt-IL } \\
71.8-72.7 \mathrm{eV}\end{array}$ \\
\hline $\mathrm{AgTaO}_{3 \_} 0.2 \% \mathrm{Pt}$ & 16.80 & 22.24 & 45.56 & 0.81 & 14.59 & - & - & - & - & - & 0.048 & 0.87 & 76.25 & 15.20 & 8.55 \\
\hline $\mathrm{AgTaO}_{3}[\mathrm{OMIM}]\left[\mathrm{BF}_{4}\right] \_0.2 \% \mathrm{Pt}$ & 15.40 & 21.96 & 46.67 & 0.82 & 13.10 & 0.46 & 0.38 & - & - & 1.22 & 0.053 & 0.85 & 69.02 & 22.21 & 8.77 \\
\hline $\mathrm{AgTaO}_{3}[\mathrm{OMIM}]\left[\mathrm{Tf}_{2} \mathrm{~N}\right] \_0.2 \% \mathrm{Pt}$ & 16.38 & 21.96 & 43.92 & 0.74 & 14.93 & 0.40 & - & 0.14 & - & 1.54 & 0.045 & 0.91 & 74.20 & 17.09 & 8.71 \\
\hline $\mathrm{AgTaO}_{3}[\mathrm{TBA}][\mathrm{Cl}] \_0.2 \% \mathrm{Pt}$ & 11.61 & 22.94 & 43.38 & 1.20 & 19.23 & - & - & - & 0.28 & 1.36 & 0.103 & 1.66 & 66.77 & 24.12 & 9.11 \\
\hline $\mathrm{AgTaO}_{3}[\mathrm{TPTZ}][\mathrm{Cl}] \_0.2 \% \mathrm{Pt}$ & 11.48 & 23.29 & 44.50 & 1.28 & 16.38 & - & - & - & 0.35 & 2.72 & 0.111 & 1.43 & 63.40 & 27.47 & 9.13 \\
\hline
\end{tabular}




\subsection{The FTIR and Raman Analyses of Lattice Vibration Modes}

The FTIR and Raman analyses carried out confirmed the obtainment of the $\mathrm{AgTaO}_{3}$ structure. The FTIR spectra of pristine and IL-modified $\mathrm{AgTaO}_{3}$ are shown in Figure S1a. All samples exhibited similar spectral features, with the most characteristic aspect being the high-intensity infrared band around 414, 542 and $831 \mathrm{~cm}^{-1}$ and corresponding to the $\mathrm{Ag}-\mathrm{O}$ bonds. The analysis revealed the presence of some characteristic peaks corresponding to ILs. For instance, for the samples modified with [TBA] $[\mathrm{Cl}]$ and [TPTZ] $[\mathrm{Cl}]$, the peaks indexed to the $\mathrm{C}-\mathrm{Cl}$ bonds were observed at around $872 \mathrm{~cm}^{-1}$. In the spectrum of $\mathrm{AgTaO}_{3 \_}[\mathrm{TPTZ}][\mathrm{Cl}]$, the band around $1025 \mathrm{~cm}^{-1}$ was additionally observed corresponding to the "in-plane" C-H bending. The bands in the region of $1320-1460 \mathrm{~cm}^{-1}$ and $1580-1620 \mathrm{~cm}^{-1}$ ascribed to the $\mathrm{C}-\mathrm{C}$ stretch (in ring) vibrations were also found. For the sample $\mathrm{AgTaO}_{3}[\mathrm{OMMIM}]$ $\left[\mathrm{Tf}_{2} \mathrm{~N}\right.$ ], the peak positioned around $438 \mathrm{~cm}^{-1}$ can be ascribed to the stretching vibration modes of S-S. Similar results were obtained by Raman spectroscopy, as presented in Figure S1b. The specific vibration modes are located around 125, 425, 488 and $601 \mathrm{~cm}^{-1}$, indicating the presence of pure phase of $\mathrm{AgTaO}_{3}$. The measured frequencies of peak positions for the samples modified by different ILs and Pt did not vary between each other. The slight differences in the intensities detected for the modified samples in comparison with the reference sample might have resulted from the preparation method.

\subsection{Optical Properties}

The UV-Vis absorption spectra of the pristine and IL-modified $\mathrm{AgTaO}_{3}$ perovskite loaded with $0.2 \mathrm{wt} \% \mathrm{Pt}$ are presented in Figure S2. It can be noted that all of the obtained samples absorbed radiation mainly in the UV-Vis region. The application of ILs did not practically influence the results. However, in the case of the IL-modified samples, the absorption intensity was higher when a co-catalyst was deposited. Furthermore, the absorption band related to $\mathrm{AgTaO}_{3}$ from 300 to $370 \mathrm{~nm}$ represented the co-catalyst-decorated samples. It was observed that the absorption band of the perovskite modified with ILs and the Pt particles in visible light increased in intensity, whereas the red shift was negligible. It might suggest that the ability to absorb the higher wavelength mainly came from Pt co-catalyst particles deposited on the surface of the $\mathrm{AgTaO}_{3}$. Platinum particles were not observed on the spectrum, probably as a result of the overlap with the absorption spectrum of $\mathrm{AgTaO}_{3}$. Similar results were observed for $\mathrm{AgMO}_{3}(\mathrm{M}=\mathrm{V}, \mathrm{Nb}, \mathrm{Ta})$ perovskite materials. The absorption band related to $\mathrm{AgTaO}_{3}$ from 200 to $350 \mathrm{~nm}$ was found in regard to the co-catalyst surface-loaded samples [33].

$\mathrm{AgTaO}_{3}$ belongs to the type of semiconductors with an indirect band gap, therefore its width was determined on the basis of the tangent lines in the plots of the square root of the Kubelka-Munk function vs. photon energy, as shown in Figure S3. It has been reported that the valence band of $\mathrm{AgTaO}_{3}$ perovskites is generally composed by $\mathrm{O} 2 \mathrm{p}$ states, which can be hybridized with $\mathrm{Ag} 4 \mathrm{~d}$ states [50]. The tangent lines, which are extrapolated to $(\mathrm{h} v \alpha)^{1 / 2}=0$, indicate the band-gap of $3.36 \mathrm{eV}$ for pristine $\mathrm{AgTaO}_{3}$ and for the IL-modified samples $3.26 \mathrm{eV}$ for [TPTZ][Cl] and [TBA][Cl] ILs and $3.30 \mathrm{eV}$ for $[\mathrm{OMIM}]\left[\mathrm{BF}_{4}\right]$ and $[\mathrm{OMIM}]\left[\mathrm{Tf}_{2} \mathrm{~N}\right] \mathrm{ILs}$, respectively. The variation in the ILs structure did not extend the absorption range into the visible light region. The band gap of the samples decorated with Pt changed in the case of the [OMIM]-based cations of ILs, and was $3.33 \mathrm{eV}$. Thus, the $\mathrm{AgTaO}_{3}$ samples can absorb light in a longer wavelength region up to visible light. The value determined for the pristine $\mathrm{AgTaO}_{3}$ perovskite was in accordance with the literature, where the band gap was around $3.4 \mathrm{eV}[51,52]$.

\subsection{Photocatalytic Activity in the Water-Splitting Reaction}

The photocatalytic activity of the obtained $\mathrm{AgTaO}_{3}$ perovskite materials for hydrogen production via photocatalytic water splitting, where methanol was used as a hole scavenger, was investigated and the results are presented in Figure 6 and Table 1 . The procedure was developed based on our previous experimental studies in the following system: sacrificial reagent-methanol; concentration of methanol- $10 \%$; amount of the photocatalyst $-0.1 \mathrm{~g}$ [48]. Before the main photocatalytic process, 
control tests were performed. The experiments in the presence of $10 \%$ methanol but without the addition of the photocatalyst revealed no $\mathrm{H}_{2}$ generation under UV-Vis irradiation. Moreover, under dark conditions, also no formation of hydrogen was detected.

(a)

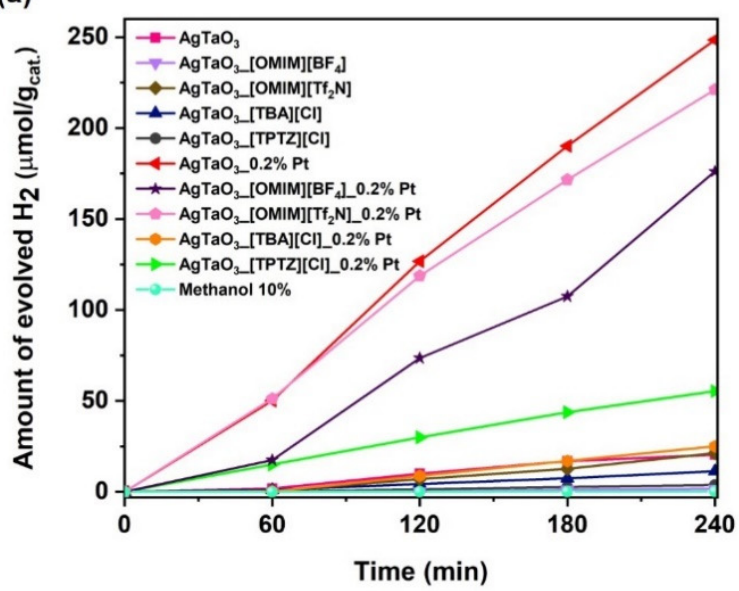

(b)

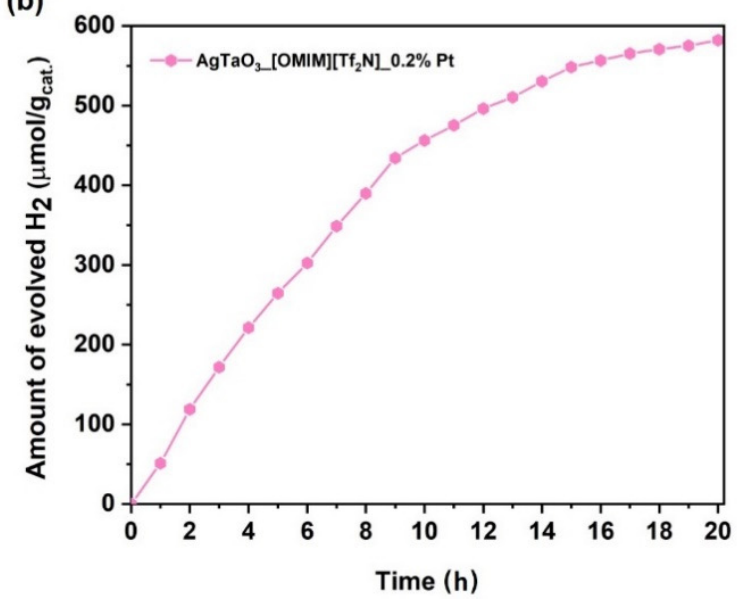

Figure 6. The amount of evolved $\mathrm{H}_{2}$ (a) under UV-Vis irradiation in the presence of the pristine and modified $\mathrm{AgTaO}_{3}$ photocatalyst, (b) under long-term UV-Vis irradiation in the presence of $\mathrm{AgTaO}_{3}[\mathrm{OMIM}]\left[\mathrm{Tf}_{2} \mathrm{~N}\right] \_0.2 \%$ Pt.

The results indicate that the presence of the Pt particles on the $\mathrm{AgTaO}_{3}$ surface significantly improved the photocatalytic activity under UV-Vis irradiation. Firstly, it was found that pristine $\mathrm{AgTaO}_{3}$ exhibited photoactivity in hydrogen production even without any co-catalyst $\left(20.4 \mu \mathrm{mol} \cdot \mathrm{g}^{-1}\right)$ hydrogen after $4 \mathrm{~h}$ of irradiation (see Figure $6 \mathrm{a}$ ). This is because the photogenerated electrons could be transferred to $\mathrm{Ag}^{+}$via the interface to accelerate the charge separation and thus influence the photocatalytic efficiency [53]. Hydrogen generation from pristine $\mathrm{AgMO}_{3}$ perovskite materials $(\mathrm{M}=\mathrm{V}, \mathrm{Nb}, \mathrm{Ta})$ was also observed by Moctezuma et al. [33]. As a result of the 3-h irradiation, they obtained $136 \mu \mathrm{mol} \mathrm{g}{ }^{-1}$ of hydrogen in the presence of $\mathrm{Na}_{2} \mathrm{SO}_{3} 0.5 \mathrm{M}$ as a sacrificial agent solution. Carrasco-Jaim et al. also received different hydrogen production efficiency (27 $\mu \mathrm{mol}$ after $3 \mathrm{~h}$ irradiation) [36]. Large differences in the efficiency of the conducted experiments could result from the different preparation route used to synthesize $\mathrm{AgTaO}_{3}$ perovskite. Secondly, we noticed that the ILs modification did not influence the enhancement of the photocatalytic activity of $\mathrm{AgTaO}_{3}$ composites compared to the reference sample. Moreover, the results show the opposite effect and the samples exhibited even lower photoactivity than the pristine $\mathrm{AgTaO}_{3}$ (see Table 1). Only application of [OMIM] [Tf $\left.2 \mathrm{~N}\right]$ caused slightly higher $\mathrm{H}_{2}$ evolution $\left(21.3 \mu \mathrm{mol} \mathrm{g}^{-1}\right)$. In the next step, we analyzed the IL-modified samples with Pt loaded at the surfaces. The largest amount of $\mathrm{H}_{2}$ was achieved for $\mathrm{AgTaO}_{3} \_.2 \% \mathrm{Pt}$ contributed to the highest $\mathrm{H}_{2}$ evolution rate, $248.5 \mu \mathrm{mol} \cdot \mathrm{g}^{-1}$ after $240 \mathrm{~min}$ under UV-Vis irradiation (almost 13 times higher than for the pristine sample). In each case, the amount of $\mathrm{H}_{2}$ evaluated was slightly different and could depend directly on the structure and properties of the ILs. Lower values of $\mathrm{H}_{2}$ production were observed for $\mathrm{AgTaO}_{3}[\mathrm{OMMIM}]\left[\mathrm{BF}_{4}\right]_{-} 0.2 \% \mathrm{Pt}\left(176.2 \mu \mathrm{mol} \cdot \mathrm{g}^{-1}\right)$ and $\mathrm{AgTaO}_{3}[\mathrm{OMIM}]\left[\mathrm{Tf}_{2} \mathrm{~N}\right]_{-} 0.2 \% \mathrm{Pt}$ $\left(221.2 \mu \mathrm{mol} \cdot \mathrm{g}^{-1}\right)$ after $240 \mathrm{~min}$ under $\mathrm{UV}$-Vis irradiation. For the samples of $\mathrm{AgTaO}_{3}$ [TPTZ] [Cl]_0.2\% $\mathrm{Pt}$ and $\mathrm{AgTaO}_{3}[\mathrm{TBA}][\mathrm{Cl}]_{-} 0.2 \%$ Pt generated almost 5 and 10 times lower amounts of $\mathrm{H}_{2}, 55.4$ and 25.1 $\mu \mathrm{mol} \mathrm{g}^{-1}$, respectively. Additionally, no other gases were detected during the process. These results indicate the possible transfer of the excited electrons and photogenerated holes from the valence band $\mathrm{AgTaO}_{3}$ after the surface Pt deposition to the conduction band. According to the literature, the low Schottky barriers of metal semiconductor surfaces act as electron traps, facilitating electron-hole separation and catalyzing the proton reduction to $\mathrm{H}_{2}$ molecules and thus the enhancement of their photoactivity [54]. 
Catalyst stability was probed by a long-term $(20 \mathrm{~h})$ hydrogen evolution test in the presence of the sample which exhibited the highest photoactivity in hydrogen generation among all modified composites, $\mathrm{AgTaO}_{3}[\mathrm{OMIM}]\left[\mathrm{Tf}_{2} \mathrm{~N}\right] \_0.2 \% \mathrm{Pt}$ (Figure 6b). As a result, hydrogen was constantly produced in the presence of the composite $\mathrm{AgTaO}_{3}[\mathrm{OMIM}]\left[\mathrm{Tf}_{2} \mathrm{~N}\right] \_0.2 \%$ Pt. The yield of hydrogen generation after $20 \mathrm{~h}$ of irradiation equaled $582.1 \mu \mathrm{mol} \mathrm{g}^{-1}$.

\subsection{Discussion of Photocatalytic Mechanism}

The $\mathrm{AgTaO}_{3} \_.2 \% \mathrm{Pt}$ sample exhibited the highest hydrogen evolution under UV-Vis irradiation $\left(248.5 \mu \mathrm{mol} \cdot \mathrm{g}^{-1}\right)$. The samples modified with different ILs, namely [OMIM][BF $\left.{ }_{4}\right],[\mathrm{OMIM}]\left[\mathrm{Tf}_{2} \mathrm{~N}\right]$, $[\mathrm{TBA}][\mathrm{Cl}]$ and [TPTZ][Cl], followed by decoration with Pt particles showed lower photoactivity in the water splitting reaction under the same conditions. The present paper aims to call into question: why does the addition of ILs suppress hydrogen evolution? Did the improvement in photoactivity originate only from the interaction between $\mathrm{AgTaO}_{3}$ and platinum? What was the role of ILs in the production of $\mathrm{H}_{2}$ ?

To answer these questions, we need to carefully examine the above-mentioned results and the mechanisms of the photocatalytic reactions analyzed previously by our group. Based on the available literature and our own experience, it is commonly known that ILs play a significant role in the increase in photoactivity in the degradation of the aqueous phenol solution, MO and RhB solution, and photocatalytic hydrogen production $[20,40,41,45,46,55,56]$. Recently, we analyzed the effect of the various ILs used in the solvothermal reaction over $\mathrm{TiO}_{2}$ particles, and the results clearly show that the significant impact on the photocatalytic performance originated directly from interaction between photocatalyst particles and ILs $[40,41,43,45]$. The photoexcitation of the $\mathrm{TiO}_{2}$ samples modified with ILs occurred directly through the formation of a surface complex which resulted in the transfer of electrons from the LUMO orbit of the ionic liquid to the conductivity band $\mathrm{TiO}_{2}$. It was found that synthesis conditions of the solvothermal route allowed for the successful decomposition of the ILs, which resulted in the incorporation of nitrogen into the $\mathrm{TiO}_{2}$ structure and thereby significantly improved the photocatalytic activity under UV-Vis and Vis irradiation [41,43]. Qi et al. also investigated the effect of ILs on the photocatalytic activity of the $\mathrm{TiO}_{2}$ semiconductor. They realized that addition of an IL with a [Bmim] $]^{+}$cation slightly enhanced the photocatalytic degradation rate of MO due to enhanced trapping and transfer of the photogenerated electrons. On the other hand, presence of an IL suppressed the degradation rate of $\mathrm{RhB}$ on the $\mathrm{TiO}_{2}$ surface by restricting the diffusion of positively charged holes to the $\mathrm{TiO}_{2}$ /solution interface [46]. On the other hand, investigation of the hydrogen evolution using IL-modified $\mathrm{SrTiO}_{3}$ perovskite followed by surface photodeposition of Pt nanoclusters did not reveal a direct correlation between the increase in $\mathrm{H}_{2}$ evolution due to the presence of the IL [48]. Furthermore, we found that the enhancement of the photoactivity originated mainly from the $\mathrm{Pt}$ loaded on the photocatalyst surface, not from the presence of the IL. In this research, we suppose that the addition of ILs during the synthesis stage (the ILs were grated with $\mathrm{Ag}_{2} \mathrm{O}$ and $\mathrm{Ta}_{2} \mathrm{O}_{5}$ in the molar ratio 1:2 vs. $\mathrm{Ag}_{2} \mathrm{O}: \mathrm{IL}$ ) could have resulted in the formation of a monolayer which stuck to the powder and decomposed during calcination in the high temperature. The XPS analysis revealed the presence of the residual elements derived from the IL, namely fluorine and boron for $\mathrm{AgTaO}_{3}[\mathrm{OMIM}]\left[\mathrm{BF}_{4}\right]$, fluorine and sulphur for $\mathrm{AgTaO}_{3}[\mathrm{OMIM}]\left[\mathrm{Tf}_{2} \mathrm{~N}\right]$ and chlorine for samples $\mathrm{AgTaO}_{3}[\mathrm{TPTZ}][\mathrm{Cl}]$ and $\mathrm{AgTaO}_{3}[\mathrm{TBA}][\mathrm{Cl}]$ (see Table 2 and Figure 5). Moreover, the FTIR measurements also confirmed the presence of bonds derived from liquids, such as $\mathrm{C}-\mathrm{Cl}$ from $[\mathrm{TBA}][\mathrm{Cl}], \mathrm{C}-\mathrm{Cl}, \mathrm{CH}$ and $\mathrm{C}-\mathrm{C}$ (in ring) from [TPTZ] [Cl], as well as S-S bonds derived from [OMIM] [Tf $\left.{ }_{2} \mathrm{~N}\right]$ (Figure S2). Additionally, it was found that the presence of ILs mainly influenced the formation of nanoparticles which consisted of granules smaller than $500 \mathrm{~nm}$, when $[\mathrm{OMIM}]\left[\mathrm{BF}_{4}\right]$ and $[\mathrm{OMIM}]\left[\mathrm{Tf}_{2} \mathrm{~N}\right]$ were used (similar morphological parameters as for pristine sample), and asymmetric cubes with a size of about $2 \mu \mathrm{m}$, for the [TBA] [Cl] and [TPTZ] [Cl] ionic liquids, respectively.

The water splitting measurements were performed firstly for the non-modified and IL-modified samples. As expected, without the co-catalyst, the samples showed very poor performance. Only the 
$\mathrm{AgTaO}_{3}[\mathrm{OMIM}]\left[\mathrm{Tf}_{2} \mathrm{~N}\right]$ showed slightly higher $\mathrm{H}_{2}$ evolution in comparison with the non-modified $\mathrm{AgTaO}_{3}$ sample (21.3 and $20.4 \mu \mathrm{mol} \cdot \mathrm{g}^{-1}$, respectively), whereas the other samples exhibited much lower photoactivity. As a result of the photodeposition of the $\mathrm{Pt}$ nanoparticles, enhanced $\mathrm{H}_{2}$ generation in comparison with the non-modified pristine sample was found. Figure 7 shows the proposed mechanism of photocatalytic $\mathrm{H}_{2}$ production under UV-Vis light irradiation in the presence of $\mathrm{AgTaO}_{3} \_\mathrm{IL} \_\mathrm{Pt}$. As a result of the absorption of UV-Vis irradiation, the photocatalyst was excited, generating pairs of charge carriers $\left(\mathrm{e}^{-}-\mathrm{h}^{+}\right)$. High-energy electrons from the conduction band were transferred to Pt particles, where they participated in the reduction of water to molecular hydrogen. Aldoni et al. achieved the same effect [57]. According to the literature, it was found that the noble metal nanoparticles adsorbed on the surface of photocatalysts provided additional reaction sites and act as effective electron traps for photogenerated electrons due to the formation of the Schottky barrier at the metal-semiconductor contact point and promotion of the charge carriers separation [58]. The highest $\mathrm{H}_{2}$ production was observed for $\mathrm{AgTaO}_{3}{ }_{0} 0.2 \% \mathrm{Pt}\left(248.5 \mu \mathrm{mol} \cdot \mathrm{g}^{-1}\right)$, whereas all the modified samples with both an IL and $\mathrm{Pt}$ possessed lower photoactivity (see Table 2 and Figure 6a). Interestingly, the Pt content for the most active sample modified with both an IL and $\mathrm{Pt}\left(\mathrm{AgTaO}_{3}[\mathrm{OMIM}]\left[\mathrm{Tf}_{2} \mathrm{~N}\right]_{-} 0.2 \% \mathrm{Pt}\right)$ was the lowest, and amounted to 0.74 at \%. Moreover, the composites which exhibited the lowest $\mathrm{H}_{2}$ evolution, $\mathrm{AgTaO}_{3}[\mathrm{TBA}][\mathrm{Cl}]_{-} 0.2 \% \mathrm{Pt}$ and $\mathrm{AgTaO}_{3}[\mathrm{TPTZ}][\mathrm{Cl}]_{-} 0.2 \% \mathrm{Pt}$, revealed the highest $\mathrm{Pt}$ concentration, 1.20 and 1.28 at.\%, respectively. In addition, the $C$ content in those composites was the highest, 19.23 and 16.23 at.\%, respectively. The C/Ag ratio for both of those samples was also the highest (see Table 2). It is evidenced that these two ILs could be adsorbed in a larger amount in the form of the residual elements derived from ILs at the composite surface, and suppressed the photoactivity in $\mathrm{H}_{2}$ generation. Therefore, even higher Pt content adsorbed on the surface of those composites did not enhance the photocatalytic efficiency.

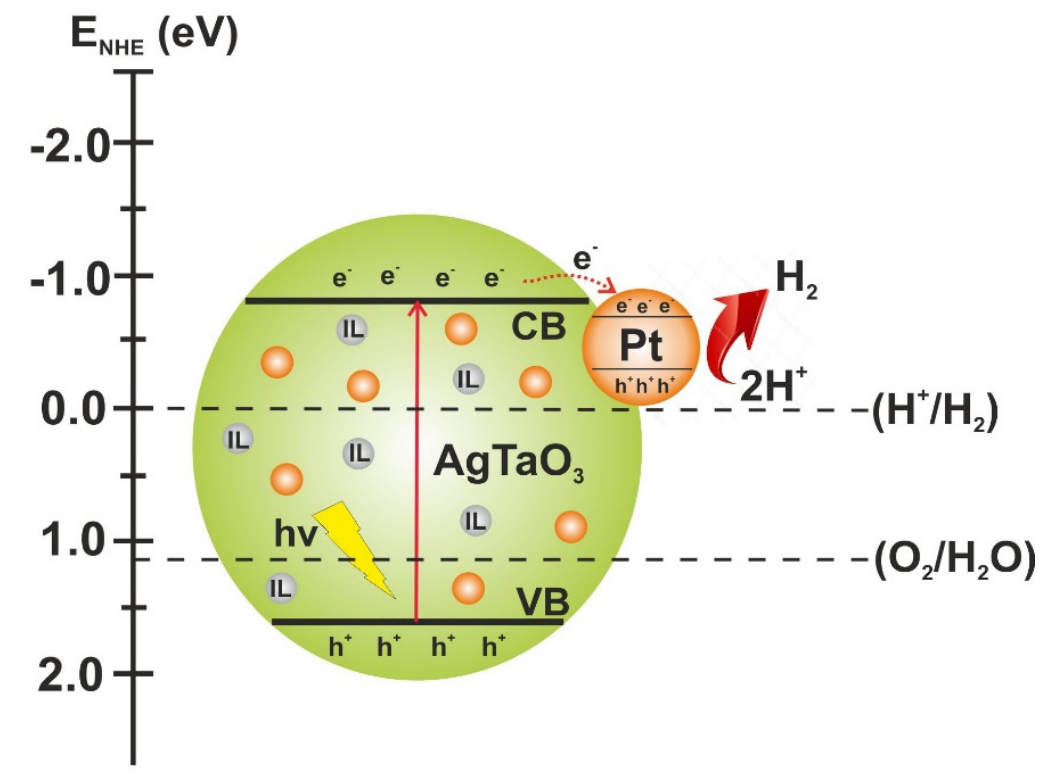

Figure 7. Proposed mechanism of photocatalytic $\mathrm{H}_{2}$ production under UV-Vis light irradiation in the presence of $\mathrm{AgTaO}_{3}$ IL_Pt.

Some literature reports associated higher $\mathrm{H}_{2}$ generation with larger specific surface area and crystallinity, which promotes more active sites for gas evolution, improving the transfer process of photogenerated charge pairs and thus enhancing the photocatalytic activity [59,60]. Based on the previously discussed experimental data, a direct relation between the increase in the BET surface area and the improvement of photocatalytic $\mathrm{H}_{2}$ production was observed. The $\mathrm{AgTaO}_{3} \mathrm{~T}_{-} \% \mathrm{Pt}$ sample possessed the largest BET surface area and also the highest hydrogen evolution compared to the other samples, $1.1408 \mathrm{~m}^{2} \cdot \mathrm{g}^{-1}$ and $248.5 \mu \mathrm{mol} \cdot \mathrm{g}^{-1}$, respectively. Hence, the samples with the 
smallest surface area, $\mathrm{AgTaO}{ }_{3}[\mathrm{TPTZ}][\mathrm{Cl}] \_0.2 \% \mathrm{Pt}\left(0.7124 \mathrm{~m}^{2} \cdot \mathrm{g}^{-1}\right)$ and $\mathrm{AgTaO}_{3}[\mathrm{TBA}][\mathrm{Cl}] \_0.2 \% \mathrm{Pt}$ $\left(0.6989 \mathrm{~m}^{2} \cdot \mathrm{g}^{-1}\right)$ generated much lower amounts of $\mathrm{H}_{2}$ (55.4 and $25.1 \mu \mathrm{mol} \cdot \mathrm{g}^{-1}$, respectively). Evidently, the addition of ILs to the reaction medium reduced the specific BET surface area and suppressed the photocatalytic activity.

\section{Conclusions}

Silver tantalate was successfully prepared via a solid-state reaction in the presence of four ILs differing in structure, namely, 2,3,5-triphenyltetrazolium chloride [TPTZ][Cl], tetrabutylammonium chloride [TBA][Cl], 1-methyl-3-octylimidazolium tetrafluoroborate [OMIM][BF 4 , 1-methyl-3-octylimidazolium bis(trifluoromethylsulfonyl)imide [OMIM][Tf $\left.{ }_{2} \mathrm{~N}\right]$, followed by surface platinum nanoparticle decoration using the photodeposition method. Morphology analysis revealed granules smaller than $500 \mathrm{~nm}$ in size when the samples were prepared in the presence of imidazolium ILs, and cubic shaped particles around $2 \mu \mathrm{m}$ in size when ammonium and tetrazolium ILs were applied. We found that the various ILs used in the synthesis did not improve the photocatalytic activity of the obtained samples in comparison to pristine $\mathrm{AgTaO}_{3}$. The enhanced hydrogen generation came only from the presence of Pt nanoparticles on the photocatalyst's surface, not from the IL modification. Despite the confirmed interactions between IL and $\mathrm{AgTaO}_{3}$ and its influence on the morphology, optical and photocatalytic properties, we suppose that ILs might block the sample surface and thus lower the photocatalytic activity. We assume that the reduced activity might result from the decomposition of the ionic liquid during the high calcination temperature, needed to obtain the final product $\mathrm{AgTaO}_{3}$. The samples which exhibited the highest $\mathrm{C}$ content (16.38 at.\% for $\mathrm{AgTaO}_{3}[\mathrm{TPTZ}]$ [Cl] and 19.23 at.\% for $\mathrm{AgTaO}_{3}[\mathrm{TBA}][\mathrm{Cl}]$ ) and platinum content (1.28 at.\% and 1.20 at.\%, respectively) were characterized by the lowest $\mathrm{H}_{2}$ evolution. Moreover, the addition of IL to the reaction environment reduced the BET specific surface area and suppressed $\mathrm{H}_{2}$ generation. Among all the obtained samples, the compound with the highest ability to photocatalytically split water $\left(248.5 \mu \mathrm{mol} \cdot \mathrm{g}^{-1}\right)$ was revealed to be $\mathrm{AgTaO}_{3} \_.2 \% \mathrm{Pt}$ (almost 13 times higher efficiency in comparison with the non-modified pristine sample), while among the modified ILs, AgTaO ${ }_{3}[\mathrm{OMIM}]\left[\mathrm{Tf}_{2} \mathrm{~N}\right] \_0.2 \% \mathrm{Pt}\left(221.2 \mu \mathrm{mol} \cdot \mathrm{g}^{-1}\right)$. Interestingly, the Pt content for this sample was the lowest, and amounted to 0.74 at.\%. Evidently, the enhanced $\mathrm{H}_{2}$ generation came from the presence of Pt nanoparticles on the composite's surface and was suppressed due to use of ILs. The Pt nanoparticles promoted charge transfer from valence band to the $\mathrm{AgTaO}_{3}$ conduction band, and inhibited the recombination probability of the photogenerated electrons and holes, which was beneficial for the improvement in the photocatalytic activity of the modified samples. As a consequence, the ILs were responsible for the decrease in photocatalytic activity in the water splitting reaction. The $\mathrm{MeOH}$ electrolyte stabilized this photocatalyst during the extended photocatalytic process.

Supplementary Materials: The following are available online at http://www.mdpi.com/1996-1944/13/18/4055/s1, Figure S1: FTIR (a) and Raman (b) spectra of pristine and corresponding ILs and Pt modified $\mathrm{AgTaO}_{3}$ samples. Figure S2: The diffusion reflection spectra of the pristine $\mathrm{AgTaO}_{3}$ photocatalyst and the corresponding ILs and Pt modified materials. Figure S3: UV-Vis Kubelka-Munk absorption of the pristine $\mathrm{AgTaO}_{3}$ photocatalyst and the corresponding ILs and Pt modified materials. Table S1: The analysis average crystallite size and amount $\mathrm{H}_{2}$ evolved.

Author Contributions: E.G.-M. supervised and directed the project; E.G.-M., J.E. and A.Z.-M. conceived the concept; J.Z., A.P., M.P.-G., M.M. and W.L. performed the experiments; J.Z., A.P., J.E. and E.G.-M. analyzed the data; J.Z., A.P., M.P.-G. and M.M. contributed reagents/materials/analysis tools; J.Z., A.P., M.P.-G. and W.L. wrote the paper. All authors have read and agreed to the published version of the manuscript.

Funding: This research was funded by the National Science Centre within the OPUS 13 programme (grant entitled: "New semiconductor materials for photocatalytic hydrogen generation: mechanism formation in the presence of ionic liquids"), contract No. 2017/25/B/ST8/01119.

Conflicts of Interest: The authors declare no conflict of interest. 


\section{References}

1. Van Ruijven, B.; Lamarque, J.-F.; van Vuuren, D.P.; Kram, T.; Eerens, H. Emission scenarios for a global hydrogen economy and the consequences for global air pollution. Glob. Environ. Chang. 2011, 21, $983-994$. [CrossRef]

2. Yildiz Bircan, S.; Matsumoto, K.; Kitagaw, K. Environmental Impacts of Hydrogen Production by Hydrothermal Gasification of a Real Biowaste. Gasif. Pract. Appl. 2012, 211-224. [CrossRef]

3. Nowotny, J.; Veziroglu, T.N. Impact of hydrogen on the environment. Int. J. Hydrog. Energy 2011, 36, 13218-13224. [CrossRef]

4. Singh, P.; Borthakur, A.; Tiwary, D.; Mishra, P. Nano-Materials as Photocatalysts for Degradation of Environmental Pollutants; Elsevier: Amsterdam, The Netherlands, 2019.

5. Balat, M. Potential Importance of Hydrogen as a Future Solution to Environmental and Transportation Problems. Int. J. Hydrog. Energy 2008, 33, 4013-4029. [CrossRef]

6. Pareek, A.; Dom, R.; Gupta, J.; Chandran, J.; Adepu, V.; Borse, P.H. Insights into renewable hydrogen energy: Recent advances and prospects. Mater. Sci. Energy Technol. 2020, 3, 319-327. [CrossRef]

7. Widera, B. Renewable hydrogen implementations for combined energy storage, transportation and stationary applications. Therm. Sci. Eng. Prog. 2020, 16, 100460. [CrossRef]

8. Asmatulu, R.; Nuraje, N.; Mul, G. Chapter 1 Introduction to Green Nanostructured Photocatalysts. In Green Photo-Active Nanomaterials: Sustainable Energy and Environmental Remediation; The Royal Society of Chemistry: London, UK, 2016; pp. 1-12.

9. Acar, C.; Dincer, I.; Naterer, G.F. Review of photocatalytic water-splitting methods for sustainable hydrogen production. Int. J. Energy Res. 2016, 40, 1449-1473. [CrossRef]

10. Li, X.; Low, J.; Yu, J. Photocatalytic Hydrogen Generation. Photocatal. Appl. 2016, 255-302. [CrossRef]

11. Owusu, P.; Asumadu Sarkodie, S. A Review of Renewable Energy Sources, Sustainability Issues and Climate Change Mitigation. Cogent Eng. 2016, 3, 1167990. [CrossRef]

12. Chen, X.; Guo, L.; Mao, Y. Semiconductor-Based Photocatalytic Hydrogen Generation. Chem. Rev. 2010, 110, 6503-6570. [CrossRef]

13. Corredor, J.; Rivero, M.; Rangel, C.; Gloaguen, F.; Ortiz, I. Comprehensive review and future perspectives on the photocatalytic hydrogen production. J. Chem. Technol. Biotechnol. 2019, 94, 3049-3063. [CrossRef]

14. Bhatt, M.D.; Lee, J.S. Nanomaterials for photocatalytic hydrogen production: From theoretical perspectives. RSC Adv. 2017, 7, 34875-34885. [CrossRef]

15. Kalamaras, C.; Efstathiou, A. Hydrogen Production Technologies: Current State and Future Developments. Conf. Pap. Energy 2013, 2013, 690627. [CrossRef]

16. Rafique, M.; Mubashar, R.; Irshad, M.; Gillani, S.; Tahir, M.B.; Khalid, N.R.; Shehzad, A.; Shehzad, M.A. A Comprehensive Study on Methods and Materials for Photocatalytic Water Splitting and Hydrogen Production as a Renewable Energy Resource. J. Inorg. Organomet. Polym. Mater. 2020, 22, 24. [CrossRef]

17. Tentu, R.D.; Basu, S. Photocatalytic water splitting for hydrogen production. Curr. Opin. Electrochem. 2017, 5, 56-62. [CrossRef]

18. Rao, V.N.; Reddy, N.L.; Kumari, M.M.; Cheralathan, K.K.; Ravi, P.; Sathish, M.; Neppolian, B.; Reddy, K.R.; Shetti, N.P.; Prathap, P.; et al. Sustainable hydrogen production for the greener environment by quantum dots-based efficient photocatalysts: A review. J. Environ. Manag. 2019, 248, 109246. [CrossRef] [PubMed]

19. Zhang, Y.; Zhang, Y.; Li, X.; Zhao, X.; Anning, C.; Crittenden, J.; Lyu, X. Photocatalytic water splitting of ternary graphene-like photocatalyst for the photocatalytic hydrogen production. Front. Environ. Sci. Eng. 2020, 14, 69. [CrossRef]

20. Tan, X.; Zhang, J.; Dongxing, T.; Jinbiao, S.; Cheng, X.; Zhang, F.; Liu, L.; Zhang, B.; Su, Z.; Han, B. Ionic liquids produce heteroatom-doped $\mathrm{Pt} / \mathrm{TiO}_{2}$ nanocrystals for efficient photocatalytic hydrogen production. Nano Res. 2019, 12, 1967-1972. [CrossRef]

21. Ravishankar, T.N.; de Vaz, O.M.; Ramakrishnappa, T.; Teixeira, S.R.; Dupont, J. Ionic liquid-assisted hydrothermal synthesis of $\mathrm{Nb} / \mathrm{TiO}_{2}$ nanocomposites for efficient photocatalytic hydrogen production and photodecolorization of Rhodamine B under UV-visible and visible light illuminations. Mater. Today Chem. 2019, 12, 373-385. [CrossRef] 
22. Hagiwara, H.; Nozawa, I.; Hayakawa, K.; Ishihara, T. Hydrogen production by photocatalytic water splitting of aqueous hydrogen iodide over Pt/alkali metal tantalates. Sustain. Energy Fuels 2019, 3, 3021-3028. [CrossRef]

23. Ismail, A.A.; Bahnemann, D.W. Photochemical splitting of water for hydrogen production by photocatalysis: A review. Sol. Energy Mater. Sol. Cells 2014, 128, 85-101. [CrossRef]

24. Ohtani, B. Photocatalysis A to Z-What we know and what we do not know in a scientific sense. J. Photochem. Photobiol. C Photochem. Rev. 2010, 11, 157-178. [CrossRef]

25. Hoffmann, M.R.; Martin, S.T.; Choi, W.; Bahnemann, D.W. Environmental Applications of Semiconductor Photocatalysis. Chem. Rev. 1995, 95, 69-96. [CrossRef]

26. Nakata, K.; Fujishima, A. $\mathrm{TiO}_{2}$ photocatalysis: Design and applications. J. Photochem. Photobiol. C Photochem. Rev. 2012, 13, 169-189. [CrossRef]

27. Kato, H.; Kudo, A. Photocatalytic Water Splitting into $\mathrm{H}_{2}$ and $\mathrm{O}_{2}$ Over Various Tantalate Photocatalysts. Catal. Today 2003, 78, 561-569. [CrossRef]

28. Wiegel, M.; Emond, M.H.J.; Stobbe, E.R.; Blasse, G. Luminescence of alkali tantalates and niobates. J. Phys. Chem. Solids 1994, 55, 773-778. [CrossRef]

29. Takasugi, S.; Tomita, K.; Iwaoka, M.; Kato, H.; Kakihana, M. The hydrothermal and solvothermal synthesis of $\mathrm{LiTaO}_{3}$ photocatalyst: Suppressing the deterioration of the water splitting activity without using a cocatalyst. Int. J. Hydrog. Energy 2015, 40, 5638-5643. [CrossRef]

30. Liu, Y.-L.; Yang, C.-L.; Wang, M.-S.; Ma, X.-G.; Yi, Y.-G. Te-doped perovskite $\mathrm{NaTaO}_{3}$ as a promising photocatalytic material for hydrogen production from water splitting driven by visible light. Mater. Res. Bull. 2018, 107, 125-131. [CrossRef]

31. Modak, B.; Ghosh, S.K. Improving visible light photocatalytic activity of KTaO3 using cation-anion dopant pair. Sol. Energy Mater. Sol. Cells 2017, 159, 590-598. [CrossRef]

32. Edalati, K.; Fujiwara, K.; Takechi, S.; Wang, Q.; Arita, M.; Watanabe, M.; Sauvage, X.; Ishihara, T.; Horita, Z. Improved Photocatalytic Hydrogen Evolution on Tantalate Perovskites $\mathrm{CsTaO}_{3}$ and $\mathrm{LiTaO}_{3}$ by Strain-Induced Vacancies. ACS Appl. Energy Mater. 2020, 3, 1710-1718. [CrossRef]

33. Carrasco-Jaim, O.A.; Torres-Martínez, L.M.; Moctezuma, E. Enhanced photocatalytic hydrogen production of $\mathrm{AgMO}_{3}(\mathrm{M}=\mathrm{Ta}, \mathrm{Nb}, \mathrm{V})$ perovskite materials using $\mathrm{CdS}$ and $\mathrm{NiO}$ as co-catalysts. J. Photochem. Photobiol. A Chem. 2018, 358, 167-176. [CrossRef]

34. Li, M.; Zhang, J.; Dang, W.; Cushing, S.K.; Guo, D.; Wu, N.; Yin, P. Photocatalytic hydrogen generation enhanced by band gap narrowing and improved charge carrier mobility in $\mathrm{AgTaO}_{3}$ by compensated co-doping. Phys. Chem. Chem. Phys. 2013, 15, 16220-16226. [CrossRef] [PubMed]

35. Wang, F.; Wang, T.; Lang, J.; Su, Y.; Wang, X. Improved photocatalytic activity and durability of $\mathrm{AgTaO}_{3} / \mathrm{AgBr}$ heterojunction: The relevance of phase and electronic structure. J. Mol. Catal. A Chem. 2017, 426, 52-59. [CrossRef]

36. Carrasco-Jaim, O.A.; Huerta-Flores, A.M.; Torres-Martínez, L.M.; Moctezuma, E. Fast in-situ photodeposition of $\mathrm{Ag}$ and $\mathrm{Cu}$ nanoparticles onto $\mathrm{AgTaO}_{3}$ perovskite for an enhanced photocatalytic hydrogen generation. Int. J. Hydrog. Energy 2020, 45, 9744-9757. [CrossRef]

37. Yang, J.; Wang, D.; Han, H.; Li, C. Roles of Cocatalysts in Photocatalysis and Photoelectrocatalysis. Acc. Chem. Res. 2013, 46, 1900-1909. [CrossRef]

38. Xu, X.; Liu, G.; Azad, A.K. Visible light photocatalysis by in situ growth of plasmonic Ag nanoparticles upon $\mathrm{AgTaO}_{3}$. Int. J. Hydrog. Energy 2015, 40, 3672-3678. [CrossRef]

39. Yu, J.; Zhang, L.; Qian, J.; Zhu, Z.; Ni, S.; Liu, G.; Xu, X. In situ exsolution of silver nanoparticles on $\mathrm{AgTaO}_{3}-\mathrm{SrTiO}_{3}$ solid solutions as efficient plasmonic photocatalysts for water splitting. Appl. Catal. B Environ. 2019, 256, 117818. [CrossRef]

40. Paszkiewicz-Gawron, M.; Gołąbiewska, A.; Pancielejko, A.; Lisowski, W.; Zwara, J.; Paszkiewicz, M.; Zaleska-Medynska, A.; Łuczak, J. Impact of Tetrazolium Ionic Liquid Thermal Decomposition in Solvothermal Reaction on the Remarkable Photocatalytic Properties of $\mathrm{TiO}_{2}$ Particles. Nanomaterials 2019, 9, 557-561. [CrossRef]

41. Paszkiewicz, M.; Łuczak, J.; Lisowski, W.; Patyk, P.; Zaleska-Medynska, A. The ILs-assisted solvothermal synthesis of $\mathrm{TiO}_{2}$ spheres: The effect of ionic liquids on morphology and photoactivity of $\mathrm{TiO}_{2}$. Appl. Catal. B Environ. 2016, 184, 223-237. [CrossRef] 
42. Yu, J.; Li, Q.; Liu, S.; Jaroniec, M. Ionic-Liquid-Assisted Synthesis of Uniform Fluorinated B/C-Codoped TiO2 Nanocrystals and Their Enhanced Visible-Light Photocatalytic Activity. Chem. Eur. J. 2013, 19, 2433-2441. [CrossRef]

43. Paszkiewicz-Gawron, M.; Długokęcka, M.; Lisowski, W.; Cristina Paganini, M.; Giamello, E.; Klimczuk, T.; Paszkiewicz, M.; Grabowska, E.; Zaleska-Medynska, A.; Łuczak, J. Dependence between Ionic Liquid Structure and Mechanism of Visible-Light-Induced Activity of $\mathrm{TiO}_{2}$ Obtained by Ionic-Liquid- Assisted Solvothermal Synthesis. ACS Sustain. Chem. Eng. 2018, 6, 3927-3937. [CrossRef]

44. Ramanathan, R.; Bansal, V. Ionic liquid mediated synthesis of nitrogen, carbon and fluorine-codoped rutile $\mathrm{TiO} 2$ nanorods for improved UV and visible light photocatalysis. RSC Adv. 2015, 5, 1424-1429. [CrossRef]

45. Łuczak, J.; Paszkiewicz-Gawron, M.; Długokęcka, M.; Lisowski, W.; Grabowska, E.; Makurat, S.; Rak, J.; Zaleska-Medynska, A. Visible light photocatalytic activity of ionic liquid- $\mathrm{TiO}_{2}$ spheres: Effect of the ionic liquid's anion structure. Chem CatChem 2017, 9, 4377-4388. [CrossRef]

46. Qi, L.; Yu, J.; Jaroniec, M. Enhanced and suppressed effects of ionic liquid on the photocatalytic activity of $\mathrm{TiO}_{2}$. Adsorption 2013, 19, 557-561. [CrossRef]

47. Muduli, R.; Kumar, P.; Panda, R.K.; Panigrahi, S. Dielectric, ferroelectric and impedance spectroscopic studies of $\mathrm{Mn}$ and $\mathrm{W}$ modified $\mathrm{AgNbO}_{3}$ ceramics. Mater. Chem. Phys. 2016, 180, 422-431. [CrossRef]

48. Zwara, J.; Paszkiewicz-Gawron, M.; Łuczak, J.; Pancielejko, A.; Lisowski, W.; Trykowski, G.; Zaleska-Medynska, A.; Grabowska, E. The effect of imidazolium ionic liquid on the morphology of Pt nanoparticles deposited on the surface of $\mathrm{SrTiO}_{3}$ and photoactivity of $\mathrm{Pt}-\mathrm{SrTiO}_{3}$ composite in the $\mathrm{H}_{2}$ generation reaction. Int. J. Hydrog. Energy 2019, 44, 26308-26321. [CrossRef]

49. Naumkin, A.V.; Kraut-Vass, A.; Gaarenstroom, S.W.; Powell, C.J. NIST X-ray Photoelectron Spectroscopy Database 20; Version 4.1. Available online: http://srdata.nist.gov/xps/ (accessed on 10 September 2020).

50. Mahmood, D.A.; Ramay, S.; Rafique, H.M.; Al-zaghayer, Y.; Khan, S. First-principles study of electronic, optical and thermoelectric properties in cubic perovskite materials $\mathrm{AgMO}_{3}(\mathrm{M}=\mathrm{V}, \mathrm{Nb}, \mathrm{Ta})$. Mod. Phys. Lett. B 2014, 28, 1450077. [CrossRef]

51. Kato, H.; Kobayashi, H.; Kudo, A. Role of Ag+ in the Band Structures and Photocatalytic Properties of AgMO3 (M: Ta and Nb) with the Perovskite Structure. Cheminform 2002, 34, 12441-12447. [CrossRef]

52. Irie, H.; Ni, L. Nb-Doped $\mathrm{AgTaO}_{3}$ as a Water-Splitting Photocatalyst Under Visible Light. ECS Meeting Abstr. 2013, 1288. [CrossRef]

53. Huo, J.; Fang, L.; Lei, Y.; Zeng, G.; Zeng, H.-P. Facile preparation of yttrium and aluminum co-doped ZnO via a sol-gel route for photocatalytic hydrogen production. J. Mater. Chem. A 2014, 2, 11040-11044. [CrossRef]

54. Chou, H.-L.; Hwang, B.J.; Sun, C.-L. Chapter 9 - Catalysis in Fuel Cells and Hydrogen Production. In New and Future Developments in Catalysis; Elsevier: Amsterdam, The Netherlands, 2013; pp. 217-270.

55. Paszkiewicz-Gawron, M.; Makurat, S.; Rak, J.; Zdrowowicz, M.; Lisowski, W.; Zaleska-Medynska, A.; Kowalska, E.; Mazierski, P.; Łuczak, J. Theoretical and Experimental Studies on the Visible Light Activity of $\mathrm{TiO} 2$ Modified with Halide-Based Ionic Liquids. Catalysts 2020, 10, 371. [CrossRef]

56. Wei, Z.; Li, R.; Wang, R. Enhanced visible light photocatalytic activity of BiOBr by: In situ reactable ionic liquid modification for pollutant degradation. RSC Adv. 2018, 8, 7956-7962. [CrossRef]

57. Naldoni, A.; D'Arienzo, M.; Altomare, M.; Marelli, M.; Scotti, R.; Morazzoni, F.; Selli, E.; Dal Santo, V. Pt and $\mathrm{Au} / \mathrm{TiO}_{2}$ photocatalysts for methanol reforming: Role of metal nanoparticles in tuning charge trapping properties and photoefficiency. Appl. Catal. B Environ. 2013, 130-131, 239-248. [CrossRef]

58. Hidalgo, M.C.; Maicu, M.; Navío, J.A.; Colón, G. Photocatalytic properties of surface modified platinised $\mathrm{TiO}_{2}$ : Effects of particle size and structural composition. Catal. Today 2007, 129, 43-49. [CrossRef]

59. Arney, D.; Hardy, C.; Greve, B.; Maggard, P. Flux Synthesis of $\mathrm{AgNbO}_{3}$ : Effect of Particle Surfaces and Sizes on Photocatalytic Activity. J. Photochem. Photobiol. A-Chem. 2010, 214, 54-60. [CrossRef]

60. Klein, M.; Nadolna, J.; Gołąbiewska, A.; Mazierski, P.; Klimczuk, T.; Remita, H.; Zaleska-Medynska, A. The effect of metal cluster deposition route on structure and photocatalytic activity of mono- and bimetallic nanoparticles supported on $\mathrm{TiO}_{2}$ by radiolytic method. Appl. Surf. Sci. 2016, 378, 37-48. [CrossRef]

(C) 2020 by the authors. Licensee MDPI, Basel, Switzerland. This article is an open access article distributed under the terms and conditions of the Creative Commons Attribution (CC BY) license (http://creativecommons.org/licenses/by/4.0/). 